\title{
Antagonism of TIM-1 blocks the development of disease in a humanized mouse model of allergic asthma
}

\author{
Sanchaita Sriwal Sonar, ${ }^{1}$ Yen-Ming Hsu, ${ }^{2}$ Melanie Lynn Conrad, ${ }^{1}$ Gerard R. Majeau, ${ }^{3}$ Ayse Kilic, ${ }^{1}$ \\ Ellen Garber, ${ }^{2}$ Yan Gao, ${ }^{2}$ Chioma Nwankwo, ${ }^{2}$ Gundi Willer, ${ }^{4}$ Jan C. Dudda, ${ }^{5}$ Hellen Kim, ${ }^{3}$ \\ Véronique Bailly, ${ }^{2}$ Axel Pagenstecher, ${ }^{6}$ Paul D. Rennert, ${ }^{3}$ and Harald Renz ${ }^{1}$ \\ 1Department of Clinical Chemistry and Molecular Diagnostics, University of Marburg, Marburg, Germany. ${ }^{2}$ Department of Drug Discovery and \\ ${ }^{3}$ Department of Molecular Discovery, Biogen Idec Inc., Cambridge, Massachusetts, USA. ${ }^{4}$ Department of Internal Medicine, Lung and Bronchial Medicine, \\ Hochgebirgsklinik, Davos, Switzerland. ${ }^{5}$ Institute of Infection Immunology, TWINCORE, Center for Experimental and Clinical Infection Research, \\ Hannover, Germany. ${ }^{6}$ Department of Neuropathology, Central Laboratory, University of Marburg, Marburg, Germany.
}

\begin{abstract}
Studies in mice and humans have revealed that the $T$ cell, immunoglobulin, mucin (TIM) genes are associated with several atopic diseases. TIM-1 is a type I membrane protein that is expressed on T cells upon stimulation and has been shown to modulate their activation. In addition to a recently described interaction with dendritic cells, TIM-1 has also been identified as a phosphatidylserine recognition molecule, and several protein ligands have been proposed. Our understanding of its activity is complicated by the possibility that TIM-1 possesses multiple and diverse binding partners. In order to delineate the function of TIM-1, we generated monoclonal antibodies directed to a cleft formed within the $\operatorname{IgV}$ domain of TIM-1. We have shown here that antibodies that bind to this defined cleft antagonize TIM-1 binding to specific ligands and cells. Notably, these antibodies exhibited therapeutic activity in a humanized SCID model of experimental asthma, ameliorating inflammation, and airway hyperresponsiveness. Further experiments demonstrated that the effects of the TIM-1-specific antibodies were mediated via suppression of Th2 cell proliferation and cytokine production. These results demonstrate that modulation of the TIM-1 pathway can critically influence activated $T$ cells in a humanized disease model, suggesting that TIM-1 antagonists may provide potent therapeutic benefit in asthma and other immune-mediated disorders.
\end{abstract}

\section{Introduction}

Allergic asthma, which can be a chronic and debilitating disease, is characterized by leukocyte infiltration into the lung, Th2 cytokine responses (classically IL-4, IL-5, and IL-13), elevated levels of allergen-specific IgE, mucus secretion, and airway hyperresponsiveness (AHR) $(1,2)$. The rising prevalence of this disease and the persistent problem of unmet medical need for severe asthmatics has stimulated intensive research in asthma genetics (3). T cell, immunoglobulin, mucin receptor molecule 1 (TIM-1), originally identified as hepatitis A virus cellular receptor 1 (HAVCR1, also known as KIM1), a kidney injury response gene in rats and humans (4) and the African green monkey (5), has also been identified as an important susceptibility gene for human asthma (3, 6). Accumulating data in the murine system support the role of TIM-1 in Th2dependent inflammation. The TIM gene family has been associated with Th2 cytokine expression and AHR (7), and anti-mouse TIM-1 mAbs reduce Th2 cytokine secretion and disease pathology in models of lung inflammation, allergic conjunctivitis, and allergic gut inflammation (8-11). However, in vivo data in the human system are lacking, and further experimental elaboration is essential to evaluate the clinical relevance of the TIM-1 pathway.

TIM proteins are type I membrane proteins with the extracellular region consisting of an $\mathrm{IgV}$ domain situated on top

Conflict of interest: Yen-Ming Hsu, Gerard R. Majeau, Ellen Garber, Yan Gao, Chioma Nwankwo, Hellen Kim, Véronique Bailly, and Paul D. Rennert are employees and stockholders of Biogen Idec Inc.

Citation for this article: J Clin Invest. 2010;120(8):2767-2781. doi:10.1172/JCI39543 of a mucin-rich domain and a short membrane-proximal stalk containing N-linked glycosylation sites (4). Murine TIM-1, TIM-2, TIM-3, and TIM-4 IgV domains show a conserved, disulfidedependent conformation in which the $\mathrm{CC}^{\prime}$ loop is folded onto the GFC $\beta$ strands, forming a unique structure. In all TIM family members the $\mathrm{CC}^{\prime}$ and $\mathrm{FG}$ strand/loop configuration $\left(\mathrm{CC}^{\prime} / \mathrm{FG}\right)$ creates a unique, variably sized cleft as identified in crystallography studies $(12,13)$. Anti-TIM-1 mAbs can be derived that are directed to this unique $\mathrm{CC}^{\prime} / \mathrm{FG}$ cleft or to distinct epitopes within the TIM-1 extracellular region.

In this study, we characterize the biochemical properties of antimouse TIM-1 and anti-human TIM-1 mAbs. To assess their activity in human allergic inflammation, we utilize the SCID mouse model. SCID mice have a defective DNA recombinase system, are therefore deficient in mature and functional $\mathrm{T}$ and $\mathrm{B}$ lymphocytes, and fail to reject allogeneic and xenogeneic tissue transplants (14-17). SCID mice transplanted with human PBMCs (hu-PBMC SCID mice) have been successfully used to study immune responses. Mice reconstituted with PBMCs from asthmatic patients develop allergic disease characterized by human Th2 cytokine secretion, allergen-specific human IgE production, lung inflammation, and AHR (18-23). Using the hu-PBMC SCID model, we demonstrate here that anti-human TIM1 mAb treatment reduces the characteristic symptoms of the asthmatic response. These data support the genetic hypothesis that TIM-1 is associated with human asthmatic disease and suggest that anti-TIM- $1 \mathrm{mAb}$ treatment might represent a novel therapy for human asthma. Furthermore, we characterize the biochemical properties of therapeutic anti-mouse 
Table 1

Binding characteristics of select rat anti-mouse TIM-1 mAbs to murine TIM-1 proteins

$\begin{array}{lccccc}\begin{array}{l}\text { Anti-mouse } \\ \text { TIM-1 mAb }\end{array} & \begin{array}{c}\text { Wild-type } \\ \text { EC }_{50} \text { (ELISA) }\end{array} & \text { Activity in vivo } & \begin{array}{c}\text { Bind mucin-stalk } \\ \text { domain }\end{array} & \begin{array}{c}\text { Bind IgV } \\ \text { domain }\end{array} & \begin{array}{c}\text { Bind F }>\text { G } \\ \text { epitope }\end{array} \\ 1 \mathrm{H} 9 & 120 \mathrm{pM} & \text { Neutral } & - & + & - \\ 1 \mathrm{H} 8 & 73 \mathrm{pM} & \text { Agonist } & + & - & - \\ 4 \mathrm{~A} 2 & 294 \mathrm{pM} & \text { Antagonist } & - & + & +\end{array}$

mAbs were assayed for their affinity and for their ability to bind murine TIM-1 proteins lacking the IgV domain, lacking the mucin/stalk domain, or lacking the $F>G$ strands and loops of the protein. ${ }^{A}$ Ref. 9. +, able to bind; - , unable to bind.

Anti-TIM-1 mAbs differentially affect PS binding. We next determined whether $\mathrm{mAbs}$ raised against murine and human TIM-1 proteins were capable of interfering with PS binding. First, using ELISA assays with Tris buffer lacking excess $\mathrm{Ca}^{++}$ or $\mathrm{Mg}^{++}$, PS binding curves for murine TIM-1 and human TIM-1 proteins were determined (Supplemental Figure 1; supplemental material available online with this article; doi:10.1172/JCI39543DS1).

TIM-1 and anti-human TIM-1 mAbs and develop a model of TIM-1 mechanism of action based on the epitopes and activities of specific $\mathrm{mAbs}$. These studies are the first to demonstrate that antagonism of human TIM-1 activity reduces pathologic immune responses in a human disease model.

\section{Results}

Biochemical characterization of anti-TIM-1 mAbs. Previously we described a panel of rat anti-mouse TIM-1 mAbs (isotype IgG2a) and showed that treatment with the anti-murine TIM-1 mAb 4A2 reduced lung inflammation in a mouse model (9). Using protease protection assays and Western blot analysis, we determined that anti-murine TIM-1 mAb 4A2 binds to a nonlinear epitope lying between the $\mathrm{F}$ strand and the $\mathrm{C}$ terminus of the $\mathrm{IgV}$ domain of mouse TIM-1 (Table 1 and our unpublished observation). Table 1 summarizes the binding characteristics of anti-mouse TIM- $1 \mathrm{mAb}$ $4 \mathrm{~A} 2$, compared with several other anti-mouse TIM-1 mAbs shown to bind to distinct domains of the mouse TIM-1 protein (9). Next we developed a panel of mouse anti-human TIM-1 mAbs (isotype IgG1). To identify anti-human TIM-1 mAbs with similar binding properties for human TIM-1, we made expression constructs in which the F and $G$ strands and intervening loop $(F>G)$ within the TIM-1 IgV domain were replaced with a murine sequence. This sequence swap encompasses one side of the cleft identified as important for mediating binding to phosphatidylserine (PS) $(13,24,25)$. The top of this cleft contains a sialic acid-like binding site $(12,26)$. We transiently expressed these constructs in 293 cells and analyzed anti-human TIM-1 mAb binding by FACS. The binding activity of anti-human TIM-1 mAb A6G2 was disrupted by the F > G human/mouse sequence substitution (Table 2). Since this $\mathrm{mAb}$ recognized a nonlinear epitope (i.e., failed to bind reduced TIM-1 protein in Western blots; data not shown), it is likely that the epitope for anti-human TIM-1 $\mathrm{mAb} A 6 \mathrm{G} 2$ is created by the disulfide-bound, 3-dimensional CC'/FG structure. Anti-human TIM-1 mAb P6A4 had a similar profile (Table 2). In contrast, other antihuman TIM-1 mAbs, shown in cross-blocking analyses to bind to distinct epitopes within the wild-type human TIM-1 IgV domain (our unpublished observation), were capable of binding to the mutated TIM-1 protein, suggesting that the overall structure of the mutant protein was not grossly affected by the sequence exchange (Table 2). The affinity of various anti-human TIM- 1 mAbs for full-length wild-type human TIM-1-Fc was determined using an ELISA format. Relative affinities were very similar among the group of $\mathrm{mAbs}$ used in this analysis and in the following experiments (Figure 1A and Table 2).
Relative $\mathrm{EC}_{50}$ values of $0.78 \mu \mathrm{g} / \mathrm{ml}$ and $0.01 \mu \mathrm{g} / \mathrm{ml}$ were obtained for human and murine TIM-1 binding, respectively. We analyzed PS binding using the human TIM-1-Fc protein in Tris buffer containing $1 \mathrm{mM} \mathrm{Ca}^{++}$and $1 \mathrm{mM} \mathrm{Mg}^{++}$, which produced an 11-fold increase in the relative affinity, to $0.07 \mu \mathrm{g} / \mathrm{ml}$. Thus the relative affinity of TIM-1 for PS binding in the ELISA assay was affected by cation levels, as expected (13).

We used the Tris buffer containing $1 \mathrm{mM} \mathrm{Ca}^{++}$and $1 \mathrm{mM} \mathrm{Mg}^{++}$ in a competition ELISA format with $3 \mu \mathrm{g} / \mathrm{ml}$ TIM-1-Fc fusion proteins and $10 \mu \mathrm{g} / \mathrm{ml}$ anti-TIM- $1 \mathrm{mAbs}$ to assess the functional activity of various anti-mouse TIM-1 mAbs and anti-human TIM-1 mAbs. Anti-TIM-1 mAbs had variable effects on PS binding. The anti-mouse TIM- $1 \mathrm{mAb} 4 \mathrm{~A} 2$ and the anti-human TIM- $1 \mathrm{mAb}$ A6G2 strongly inhibited binding of PS to the murine and human fusion proteins, respectively (Figure 1, B and C).

Anti-TIM-1 mAbs 4A2 and A6G2 ablate cation-independent binding to $D C s$. TIM-1 possesses both cation-dependent and cation-independent binding activity on mouse DCs (26). To characterize TIM-1 binding to DCs, we incubated mouse TIM-1-Fc or mouse TIM-1$\mathrm{IgV}-\mathrm{Fc}$ protein with murine bone marrow-derived myeloid DCs in the presence or absence of excess chelating agents and anti-mouse TIM-1 mAbs, and performed FACS analyses. Both the murine TIM-1-Fc and TIM-1-IgV-Fc proteins bound to DCs (Figure 2, A and B). EGTA (1 mM) (or $1 \mathrm{mM}$ EDTA; data not shown) reduced binding of murine TIM-1-Fc to DCs (Figure 2A), as previously described (26). Importantly, the binding of murine TIM-1 to these DCs required only the IgV domain (Figure 2B). To further demonstrate the specificity of TIM-1-Fc binding to DCs, we used a vari-
Table 2

Binding characteristics of select anti-human TIM-1 mAbs

$\begin{array}{lcccc}\begin{array}{l}\text { Anti-human } \\ \text { TIM-1 mAb }\end{array} & \begin{array}{c}\text { Wild-type } \\ \text { EC }_{50} \text { (ELISA) }\end{array} & \begin{array}{c}\text { Bind IgV } \\ \text { domain }\end{array} & \begin{array}{c}\text { Bind F strand } \\ \text { mutant }\end{array} & \begin{array}{c}\text { Bind F strand } \\ \text { G strand mutant }\end{array} \\ \text { A3H1 } & 27 \mathrm{pM} & + & + & + \\ \text { P3A3 } & 20 \mathrm{pM} & + & + & + \\ \text { A8E5 } & 67 \mathrm{pM} & + & + & + \\ \text { AWE2 } & 26 \mathrm{pM} & + & + & + \\ \text { A6G2 } & 27 \mathrm{pM} & + & +/- & - \\ \text { P6A4 } & 33 \mathrm{pM} & + & - & -\end{array}$

$m A b s$ were assayed for their affinity using an ELISA format; relative affinities are shown. mAbs were further assayed by ELISA and FACS analyses and for their ability to bind the human TIM-1 IgV domain and to human TIM-1 proteins in which specific $\beta$ strands and adjacent loops were mutated to the murine sequence. The $F$ strand mutant contained the murine amino acids LYCCRVEIP in place of the corresponding human sequence. The $F$ strand $>G$ strand mutant contained the above substitution plus the murine amino acids QKVTFSLQVK in place of the corresponding human sequence. + , able to bind; -, unable to bind. 

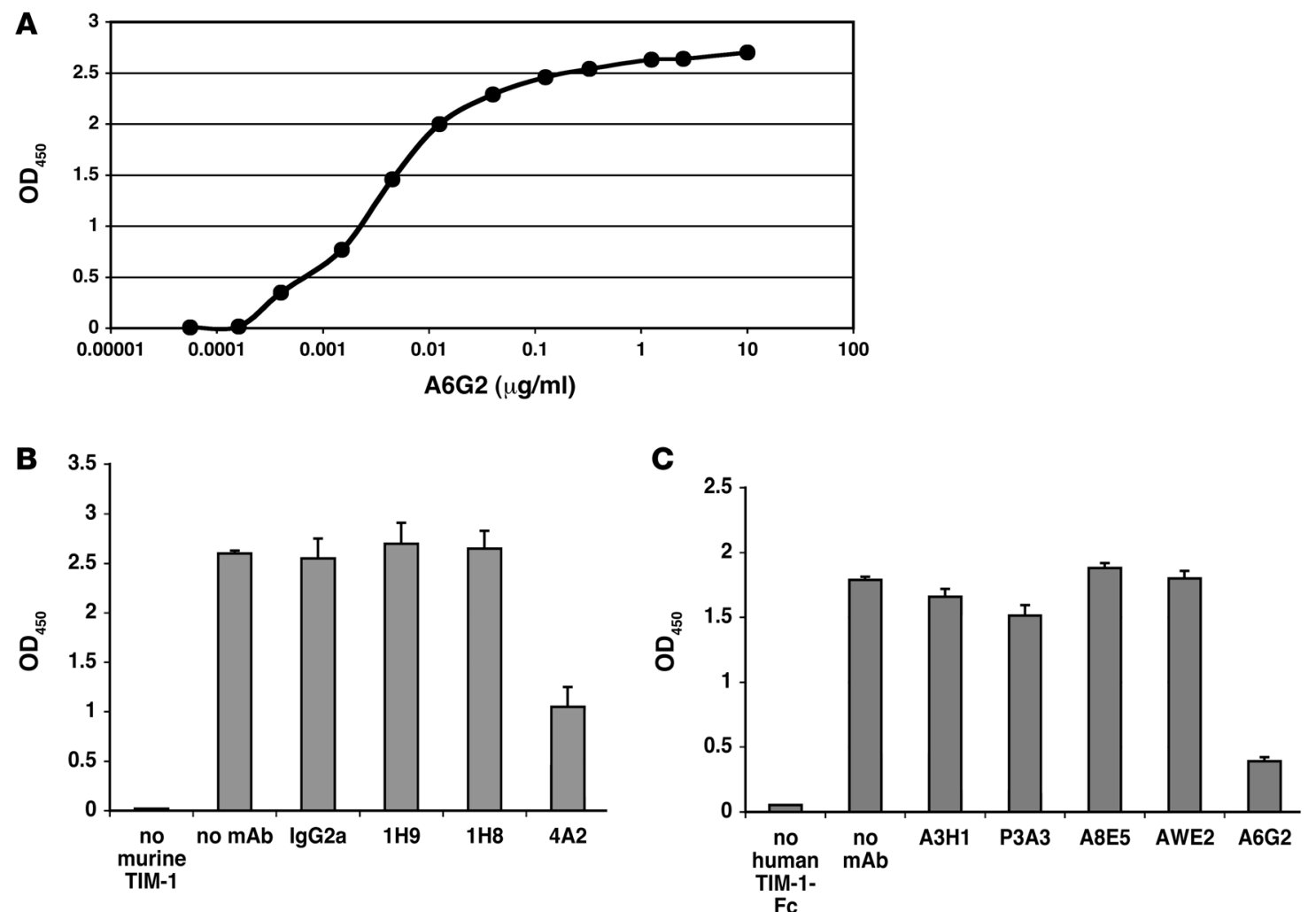

Figure 1

Binding and blocking activities of anti-TIM-1 mAbs. (A) Representative ELISA binding curve showing anti-human TIM-1 mAb A6G2 binding to immobilized human TIM-1-Fc. The relative $\mathrm{EC}_{50}$ after curve fitting was calculated to be $4 \mathrm{ng} / \mathrm{ml}(26.7 \mathrm{pM})$. (B and C) Reduction of TIM-1 binding to PS by anti-TIM-1 mAbs. Anti-mouse TIM-1 mAb 4A2 reduced the binding of murine TIM-1-Fc to PS by $63 \%$ (B), while anti-human TIM-1 mAb A6G2 reduced the binding of human TIM-1-Fc to PS by $78 \%$ (C).

ety of blocking reagents including $5 \%$ human sera, $20 \mu \mathrm{g} / \mathrm{ml}$ heataggregated human IgG, or $10 \%$ rabbit sera. None of these reagents had a significant impact on binding (Supplemental Figure 2 and data not shown). Furthermore, we used irrelevant human receptor-IgG1 Fc fusion proteins at the same concentration as the human TIM-1-IgG1 Fc $(3 \mu \mathrm{g} / \mathrm{ml})$ to stain CD11 $\mathrm{c}^{+}$DCs in human PBMC preparations. Neither CD 40-Fc nor LT $\beta$ R-Fc bound to DCs in this assay (Supplemental Figure 2), as would be expected.

Anti-mouse TIM-1 mAb 4A2 reduced binding of murine TIM-1 proteins to DCs in the presence of $1 \mathrm{mM}$ EGTA (Figure 2A and Table 3) to background level, similar to the unstained control (data not shown). Other anti-mouse TIM-1 mAbs or rat IgG2a isotype control $\mathrm{mAb}$ did not affect binding of the TIM-1 fusion proteins to murine myeloid DCs in the presence of $1 \mathrm{mM}$ EGTA (Table 3). Similar results were obtained using CD $11 c^{+}$mouse DCs freshly isolated from mouse blood (data not shown). LPS-activated murine myeloid DCs had increased levels of CD80, CD86, and MHC-II staining in FACS analyses (data not shown). Activation of these DCs increased the level of TIM-1-Fc binding (the MFI increased from 351 to 471), and this increase was blocked with EGTA and anti-TIM-1 mAb 4A2 similarly to nonactivated DCs (Figure 2C). These results demonstrate that TIM-1 binds to DCs even in the presence of excess chelating agents, as originally described by Murphy and colleagues (26), is dependent on the TIM-1-IgV domain, and is selectively ablated by an anti-mouse TIM- $1 \mathrm{mAb}$ that binds the $\mathrm{IgV}$ domain within the $\mathrm{F}>\mathrm{G}$ region proposed as critical for multiple TIM-1 binding activities $(13,24,25)$.
To determine whether anti-human TIM-1 mAb A6G2 had a similar impact on human TIM- 1 interaction with human DCs, CD34 stem cells were cultured to derive myeloid DCs, kept in culture or activated with LPS for 48 hours, then incubated with $5 \mu \mathrm{g} / \mathrm{ml}$ TIM-1-Fc protein in the presence or absence of 1-2 mM EGTA and $10 \mu \mathrm{g} / \mathrm{ml}$ anti-human TIM-1 mAbs or control mAb. Similar to the findings using the mouse system, anti-human TIM-1 mAb A6G2 was able to block TIM-1 protein binding to myeloid DCs in the presence of 1-2 mM EGTA (Figure 2D and data not shown). The level of staining in the presence of both mAbs and EGTA was similar to the background staining observed with the unstained control (data not shown). Incubation of anti-human TIM-1 mAb A6G2 with human PBMC preparations blocked TIM-1-Fc binding on activated $\mathrm{CD} 11 \mathrm{c}^{+} \mathrm{DCs}$, similar to the results obtained using anti-murine TIM-1 mAb 4A2 (Figure 3A). In contrast, TIM-1$\mathrm{Fc}$ binding to other cell populations including $\mathrm{CD}^{+} \mathrm{T}$ cells and $\mathrm{CD} 19^{+} \mathrm{B}$ cells was negligible. This suggested that the robust binding seen in specific DC populations was unique to DCs and not solely associated with PS recognition.

To further test the hypothesis that $\mathrm{mAb}$ interaction with the $\mathrm{F}>\mathrm{G}$ region was associated with antagonistic activity in the $C D 11 c^{+} D C$ binding assays, we screened 27 additional anti-human TIM-1 mAbs raised against the $\mathrm{IgV}$ domain. Within this panel of mAbs, the only additional $\mathrm{mAb}$ capable of antagonizing human TIM-1-Fc binding to CD11 $\mathrm{c}^{+} \mathrm{DCs}$ was P6A4, another mAb shown to bind to the $\mathrm{F}>\mathrm{G}$ region in the domain mutagenesis experiments (Table 2 and Figure $3 \mathrm{~B}$ ). Thus, we found that in both the mouse and human 


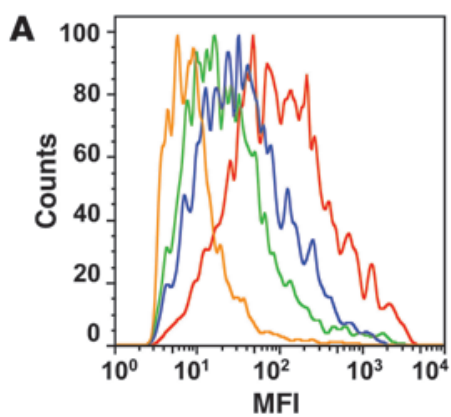

Murine TIM-1-Fc

Murine TIM-1-Fc + EGTA

Murine TIM-1-FC + 4A2

Murine TIM-1-Fc + EGTA + 4A2

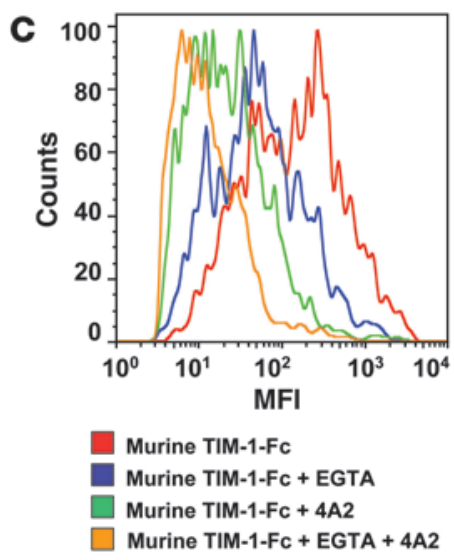

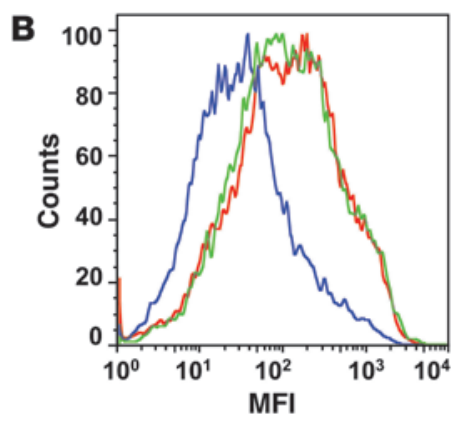

Murine TIM-1-IgV-Fc

Murine TIM-1-IgV-Fc + 4A2

$\square$ Murine TIM-1-IgV-Fc + control mAb

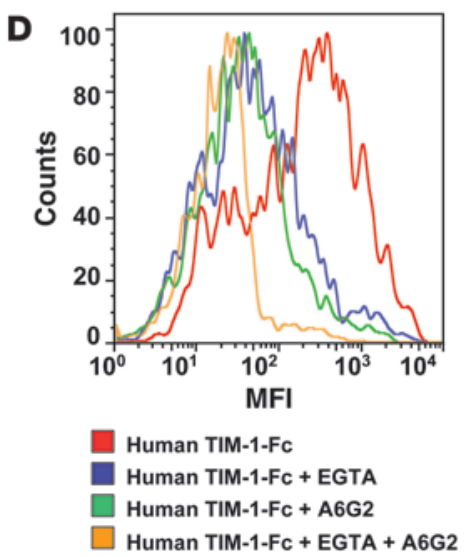

Figure 2

TIM-1 protein binding to DCs and blockade using anti-TIM1 mAbs. (A) Binding of murine TIM-1-Fc to bone marrowderived murine myeloid $D C s$ in the presence or absence of EGTA and the anti-mouse TIM-1 mAb 4A2. TIM-1 binding was reduced by EGTA and by mAb 4A2. (B) Binding of murine TIM-1-IgV-FC to bone marrow-derived murine myeloid DCs in the presence or absence of the anti-mouse TIM-1 mAb 4A2. The IgV domain was sufficient to mediate binding to myeloid DCs, and this binding was reduced by anti-mouse TIM-1 mAb 4A2. (C) Binding of murine TIM-1-FC to LPS-activated bone marrow-derived murine myeloid DCs in the presence or absence of EGTA and the anti-mouse TIM-1 mAb 4A2. LPS activation increases TIM-1 binding to myeloid DCs, and this increased binding was reduced by EGTA and by anti-mouse TIM-1 mAb 4A2. (D) Binding of human TIM-1-FC to human $\mathrm{CD}_{34}{ }^{+}$stem cell-derived myeloid DCs in the presence or absence of EGTA and the anti-human TIM-1 mAb A6G2. TIM-1 binding was reduced by EGTA and by the anti-human TIM-1 mAb A6G2. systems, only those mAbs that interacted with the region of TIM-1 $\mathrm{IgV}$ domain containing the $\mathrm{F}>\mathrm{G}$ strands and loop reduced TIM-1 binding to cultured myeloid DCs or to freshly obtained CD11 $c^{+}$DCs. We then compared the pattern of binding of human TIM-1-Fc to DCs with that of Annexin-V, a canonical PS ligand, using FACS analysis. Freshly isolated CD $11 \mathrm{c}^{+}$DCs from human PBMCs bound Annexin- $V$ at a low level in a manner that was very sensitive to the presence of chelating agent ( $1 \mathrm{mM}$ EDTA), giving a specific MFI of 88 . In contrast, human TIM-1-Fc bound DCs with a specific MFI of 144 even in the presence of 2 mM EGTA. Incubation with 1 mM EGTA or 1-2 mM EDTA gave similar results. In all cases TIM-1-Fc binding was reduced to background levels (MFI 18) by incubation with anti-human TIM-1 mAb A6G2. To compare the level of PS staining on freshly isolated DCs with that on apoptotic cells, DCs were treated with $1 \mu \mathrm{M}$ staurosporin. Apoptotic DCs showed dramatically increased Annexin- $V$ binding with an MFI of 4,162 . These results suggest that TIM-1 binding to DCs in the presence of excess chelating agents may be mediated by a molecule other than PS. Importantly, the strikingly similar biochemical behavior of the anti-human TIM-1 mAb A6G2 to its murine counterpart 4A2 motivated testing its therapeutic efficacy in an in vivo system.

Human cytokines and TIM-1 are upregulated in a bu-PBMC SCID mouse model of allergic asthma. To determine whether anti-human TIM-1 mAb A6G2 could reduce the symptoms of experimental allergic asthma as does the anti-murine TIM-1 mAb 4A2 (9), a model using hu-PBMC SCID mice was established (Figure 4). As described previously $(22,23)$, SCID mice were reconstituted i.p. with PBMCs from asthmatic donors allergic to the house dust mite Dermatophagoides pteronyssinus allergen. Following reconstitution, recipient mice received multiple i.p. sensitizations with $D$. pteronyssinus to maintain and boost the allergen-specific immune response and were subsequently challenged with aerosolized $D$. pteronyssinus to trigger the allergic asthmatic phenotype (Figure 4). Using this protocol, a cohort was included to evaluate the effect of anti-human TIM-1 mAb A6G2 treatment (Table 4). Additional cohorts (Table 4) included an irrelevant isotype IgG control, an anti-human IL-13 mAb, and an anti-human TIM-1 $\mathrm{mAb}, \mathrm{A} 3 \mathrm{H} 1$, whose epitope lies in a region of the human TIM-1 $\mathrm{IgV}$ domain that is distinct from that recognized by anti-human TIM-1 mAb A6G2 (Table 1 and our unpublished observation).

Table 3

Characterization of rat anti-mouse TIM-1 mAb activity

\begin{tabular}{lccc}
\hline mAb & $\begin{array}{c}\text { In vivo } \\
\text { activity }\end{array}$ & $\begin{array}{c}\text { Block binding: } \\
\text { TIM-1-FL-Fc }\end{array}$ & $\begin{array}{c}\text { Block binding: } \\
\text { TIM-1-IgV-Fc }\end{array}$ \\
Rat IgG2a & Isotype control & No & No \\
$1 \mathrm{H} 9$ & Neutral & No & No \\
$1 \mathrm{H} 8$ & Activating & No & No \\
$4 \mathrm{~A} 2$ & Antagonizing & Yes & Yes \\
\end{tabular}

The in vivo activity of the listed mAbs is summarized (9). The ability of mAbs to block interaction of full-length and IgV domain-specific murine TIM-1 fusion proteins with murine myeloid DCs was assayed by FACS analysis. 
A

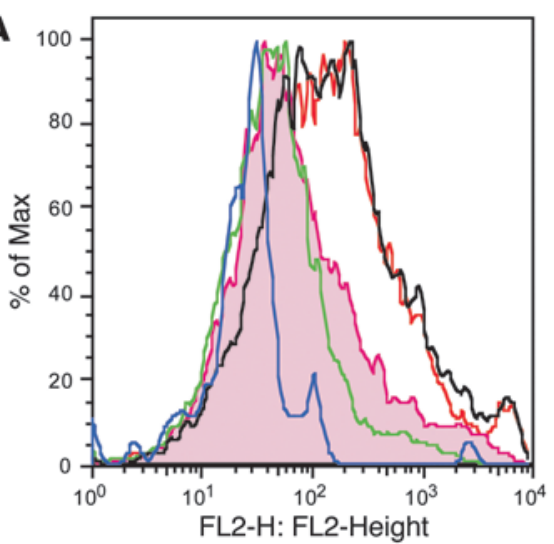

unstained

human TIM-1-Fc

human TIM-1-Fc + isotype control

human TIM-1-Fc + A6G2

human TIM-1-Fc + A6G2 + EGTA
B

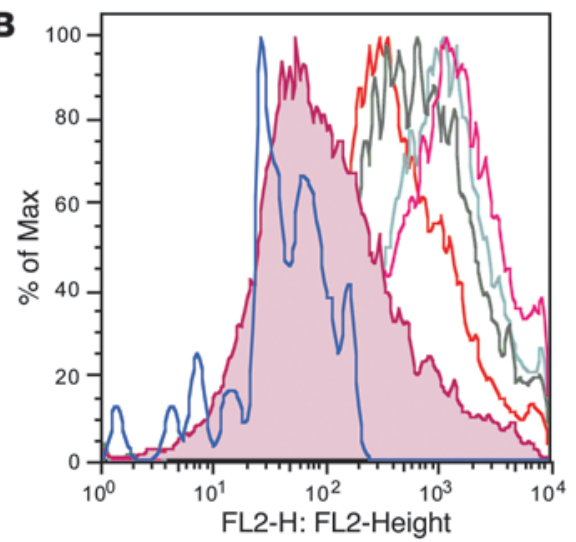

unstained

human TIM-1-Fc +AWE2

human TIM-1-Fc + A8E5

human TIM-1-Fc + A3H1

human TIM-1-Fc + P3A3

human TIM-1-Fc + P6A4

\section{Figure 3}

Human TIM-1 protein binding to human CD11 $\mathrm{C}^{+}$DCs and blockade using antihuman TIM-1 mAbs. (A) Binding of human TIM-1-FC to LPS-activated CD11C+ DCs from PBMCs in the presence of antihuman TIM-1 mAb A6G2 or isotype control (MOPC21). (B) Binding of human TIM-1-Fc to LPS-activated CD11 $\mathrm{c}^{+}$DCs from PBMCs in the presence of various anti-human TIM-1 IgV domain mAbs.
The neutralizing anti-human IL-13 mAb was included as a putative positive control (27). Negative control mice were reconstituted with PBMCs from nonallergic donors. All groups were subsequently challenged with aerosolized $D$. pteronyssinus.

Asthmatic hu-PBMC SCID mice had an increase in leukocyte numbers and human IL-4 levels (Table 5 and Figure 5A), unaltered IFN- $\gamma$ and TNF- $\alpha$ in bronchoalveolar lavage fluid (BALF) (Figure 5, B and C), as has been described previously (28), lung tissue inflammation (Figure 5D), and AHR (Table 5). Infiltration of human mononuclear cells was observed only around vessels and airways of mice receiving asthmatic PBMCs (Figure 5D). Importantly, quantitative PCR (qPCR) analysis revealed a marked increase in the level of human TIM1 mRNA in the lungs of D. pteronyssinus-sensitized and -challenged asthmatic hu-PBMC SCID mice compared with nonallergic donor control mice, when normalized to human ribosomal L32 (Figure 5E). The TIM1 mRNA detected likely represents both mucin domain variants of human TIM-1 (having or lacking the 5-amino acid insertion at position 158), as RT-PCR and sequencing analysis have revealed expression of both variants in human PBMC, tonsil, and other tissue samples from multiple donors (our unpublished observation). Examination of murine TIM-1 expression by qPCR revealed lowlevel expression that was not affected by the treatment protocol (Figure 5E). Induction of the asthmatic phenotype was dependent on consecutive challenges with $D$. pteronyssinus, as previously described (21), and the presence of human asthmatic cells, since transfer of nonallergic cells had no effect (Table 5). We did not detect eosinophils or neutrophils in the hu-PBMC SCID system, due to absence of these cell types in the transferred populations, confirming previous observations (29).

Anti-human TIM-1 mAb A6G2 prevents development of experimental asthma. We next tested anti-human TIM-1 mAb A6G2 for therapeutic activity in the hu-PBMC SCID model of experimental asthma (Table 4). Mice treated with anti-human TIM-1 mAb A6G2 had a markedly reduced influx of leukocytes into the airways (Table 5). Measurement of cytokines in the BALF and lung homogenates of anti-human TIM-1 mAb A6G2-treated mice revealed a strong reduction of human IL-4, whereas no signifi- cant changes in the IFN- $\gamma$ or TNF- $\alpha$ levels were observed (Table 5 and Figure 5, A-C). The reduction in lung inflammation with anti-human TIM-1 mAb A6G2 was comparable to that observed with the anti-human IL-13 mAb, while the isotype control $\mathrm{mAb}$ (IgG) and anti-human TIM-1 mAb A3H1 had no effect on these readouts (Table 5). Anti-human TIM-1 mAb $3 \mathrm{H} 1$ binds to human TIM-1 with similar affinity as anti-human TIM-1 mAb A6G2 but binds to a distinct epitope (Table 2 and our unpublished observation).

In addition, AHR substantially improved in mice treated with anti-human TIM-1 mAb A6G2 or anti-human IL-13 mAb. Neither the isotype control antibodies nor anti-human TIM-1 mAb $\mathrm{A} 3 \mathrm{H} 1$ affected the outcome of AHR, with values comparable to the positive control (Table 5). Finally, neither anti-human TIM-1 mAb A6G2 nor anti-human IL-13 mAb treatment affected the migration and homing of asthmatic PBMCs from the site of injection, showing that the therapeutic effects in the lung were not due to differences in cell transfer efficiency (data not shown). These data demonstrate the therapeutic efficacy of anti-human TIM-1 mAb A6G2 in a humanized mouse model of asthma.

$\mathrm{CD} 4^{+} \mathrm{T}$ cells represent the dominant cell type in asthmatic SCID lungs and selectively express TIM1. Having observed upregulation of human TIM1 mRNA in the lungs of asthmatic hu-PBMC SCID mice, we further investigated possible cellular sources of human TIM-1. Due to the relatively low number of human cells migrating into the lungs of hu-PBMC SCID mice, further characterization of TIM-1 expression was carried out in donor cells using ex vivo assays. For this purpose donor $\mathrm{CD}^{+} / \mathrm{CD}^{+}$and $\mathrm{CD}^{+} / \mathrm{CD}^{+} \mathrm{T}$ cells, $\mathrm{CD} 14^{+}$ monocytes, and $\mathrm{CD} 19^{+} / \mathrm{CD} 20^{+} \mathrm{B}$ cells were purified from PBMCs by cell sorting and the expression of TIM1 mRNA was analyzed by qPCR. Human TIM1 mRNA was detected in $\mathrm{CD}^{+} / \mathrm{CD}^{+} \mathrm{T}$ cells from asthmatic donors, but not from nonallergic donors (Figure 6, $\mathrm{A}$ and $\mathrm{B})$. In contrast, $\mathrm{CD}^{+} / \mathrm{CD}^{+}, \mathrm{CD} 14^{+}$, and $\mathrm{CD} 19^{+} / \mathrm{CD} 20^{+}$ cells from asthmatics or nonallergic mice did not express TIM1 mRNA (Figure 6A), while DC populations constitutively expressed low levels of TIM1 RNA that was not affected by the asthmatic phenotype (Figure 6, C and D). We were unable to detect surface TIM-1 protein on $\mathrm{CD}^{+} \mathrm{T}$ cells by FACS analysis. Therefore we fur- 


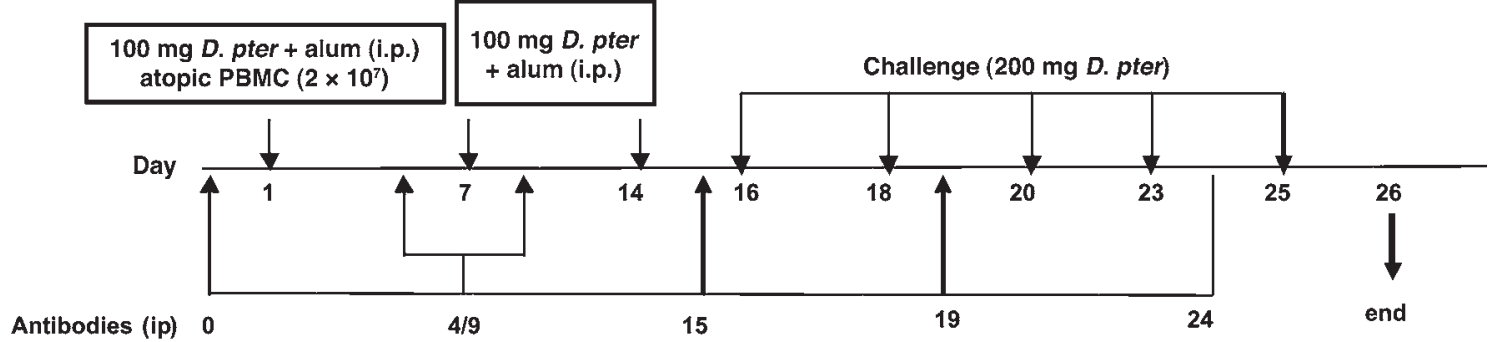

Figure 4

Protocol for induction of experimental asthma in hu-PBMC SCID mice. Diagram of the protocol showing antibody delivery, allergen sensitization, and challenge time points. Animals were reconstituted with $2 \times 10^{7}$ PBMCs on day 1. D. pter, D. pteronyssinus; alum, aluminium hydroxide adjuvant.

ther investigated the immune cell types infiltrating the lungs of hu-PBMC SCID mice. Using immunohistochemical (IHC) staining for human CD4, CD8, CD20, and CD68, we found that the inflammatory infiltrates consisted predominantly of human $\mathrm{CD}^{+}$ $\mathrm{T}$ cells, while lower numbers of $\mathrm{CD}^{+} \mathrm{T}$ cells were observed (Figure $6 \mathrm{E})$. Occasionally a CD20 $\mathrm{B}$ cell was observed, but no $\mathrm{CD} 68^{+}$ macrophages were detected. These results suggest that pathogenic $\mathrm{T}$ cells represent a major target of TIM-1 antagonism in the asthmatic hu-PBMC SCID mice.

TIM-1 antagonism suppresses $T$ cell proliferation. To further evaluate the mechanism of anti-TIM-1 mAb A6G2 treatment, we examined the effect of TIM-1 blockade on the expression levels of transcription factors indicative of $\mathrm{T}$ cell effector subsets including Th1 and Th2 cells and Tregs in the lungs of the hu-PBMC SCID mice (Figure 7, A-D). Anti-human TIM-1 mAb A6G2 treatment resulted in the downregulation of the Th2-associated transcription factors GATA-3 and c-Maf and an increase in Treg-associated FoxP3 expression (Figure 7, A-C), while Tbet mRNA levels remained undetectable (Figure 7D). The increase in FoxP3 levels was not associated with a detectable increase in IL-10 levels or the number of FoxP3 ${ }^{+}$cells in BALF (data not shown). Furthermore, mRNA expression of the Th17 cell-associated transcription factors RORgt and RORa were below detection levels. These data are consistent with the BALF cytokine profile indicating that anti-human TIM-1 mAb A6G2 affects the development of a Th2 phenotype required for establishment of asthma.

There are a variety of potential mechanisms of action that might explain the activity of the anti-human TIM-1 mAb A6G2, including the reduction of Th2 $\mathrm{T}$ cell numbers and/or suppression of cytokine production by individual Th2 T cells. We therefore determined the frequency of IL-4-producing $\mathrm{T}$ cells by intracellular cytokine staining and FACS analysis (Figure 7, E and F).
Treatment of the cultures with anti-human TIM-1 mAb A6G2 significantly blocked the $D$. pteronyssinus-induced increase in the frequency of IL-4-producing T cells. Also, polyclonal stimulation of human PBMCs with anti-CD3/anti-CD28 antibodies in the presence of anti-human TIM-1 mAb A6G2 resulted in a strong downregulation of Th2 cytokine production, including IL-4 (Figure 7G), but had no effect on IFN- $\gamma$ production levels (Figure 7H). To examine whether the observed effects of antihuman TIM-1 mAb A6G2 were due to selective inhibition of Th2 cell proliferation, a BrdU incorporation assay was utilized. Incubation of activated asthmatic T cells with anti-human TIM-1 mAb A6G2 strongly suppressed T cell proliferation (Figure 7I) without causing any apparent cell depletion. Similar results were obtained using anti-CD3/anti-CD28 activated T cells harvested from the spleens of hu-PBMC SCID mice reconstituted with cells from asthmatic donors (Figure 7J). Taken together, these results suggest that the effect of anti-human TIM-1 mAb A6G2 on the frequency of IL-4-producing T cells and Th2 cytokine production is due to suppression of $\mathrm{T}$ cell proliferation.

Anti-buman TIM-1 mAb A6G2 inbibits D. pteronyssinus-induced activation of autologous $C D 4^{+} T$ cells by $D C$. To examine whether anti-human TIM-1 mAb A6G2 affects functional DC-T cell interaction, CD14 ${ }^{+}$ monocytes from allergic asthmatic donors or nonallergic control donors were cultured to derive myeloid DCs. These myeloid DCs were co-cultured with autologous $\mathrm{CD}^{+} \mathrm{T}$ cells. $\mathrm{CD} 4^{+} \mathrm{T}$ cells and myeloid DCs, when cultured alone for 5 days, did not proliferate (Figure 7K), and IL-5 secretion was negligible (Figure 7L). In contrast, $\mathrm{CD}^{+} \mathrm{T}$ cells when cultured together with myeloid DCs from allergic asthmatic but not nonallergic controls proliferated strongly and produced IL-5 (Figure 7, K and L). Anti-human TIM-1 mAb A6G2 reduced proliferation and IL-5 production to background levels (Figure 7, K and L), suggesting that D. pteronyssinus-induced $\mathrm{T}$ cell

Table 4

Experimental cohorts of hu-PBMC SCID mice receiving various treatments

\begin{tabular}{|c|c|c|c|c|c|c|c|}
\hline & Negative control & Negative control & Positive control & $\lg G$ & Anti-IL-13 & A6G2 & A3H1 \\
\hline Donor & Nonallergic & Nonallergic & Allergic/asthmatic & Allergic/asthmatic & Allergic/asthmatic & Allergic/asthmatic & Allergic/asthmatic \\
\hline Sens/chall & $-1+$ & t/+ & $+/+$ & t/t & $+/+$ & $+/+$ & $+/+$ \\
\hline $\lg G$ & - & - & - & + & - & - & - \\
\hline Anti-IL-13 & - & - & - & - & + & - & - \\
\hline A6G2 & - & - & - & - & - & + & - \\
\hline $\mathrm{A} 3 \mathrm{H} 1$ & - & - & - & - & - & - & + \\
\hline
\end{tabular}

Sens/chall, sensitization and challenge. 


\section{Table 5}

Effect of antibody treatment on $D$. pteronyssinus-induced AHR, human IL-4 production, and BAL leukocyte numbers in hu-PBMC SCID mice

$\begin{array}{lccccc}\text { Donor } & \text { Sens/chall } & \text { Treatment } & \text { AHR }\left(\mathbf{M C h}_{50} ; \mathbf{m g} / \mathbf{m l}\right) & \text { BALF human IL-4 }(\mathbf{p g} / \mathbf{m l}) & \text { BAL leukocytes }\left(\mathbf{1 0}^{4}\right) \\ \text { NA } & -/+ & \text { PBS } & 107.9 \pm 11.35 & \text { ND } & 13.9 \pm 2.0 \\ \text { NA } & +/+ & \text { PBS } & 94.5 \pm 5.5 & \text { ND } & 11.4 \pm 2.3 \\ \text { A } & +/+ & \text { PBS } & 68.9 \pm 6.4 & 8.1 \pm 0.8^{\mathrm{A}} & 19.3 \pm 2.1^{A}, \mathrm{~B} \\ \text { A } & +/+ & \text { IgG } & 73.8 \pm 9.7^{C} & 7.6 \pm 3.0^{\mathrm{C}} & 16.5 \pm 1.5^{\mathrm{C}} \\ \text { A } & +/+ & \text { Anti-IL-13 } & 113.5 \pm 11.0^{\mathrm{A}} & 4.9 \pm 1.7 & 10.5 \pm 2.6^{\mathrm{A}} \\ \text { A } & +/+ & \text { A3H1 } & 87.3 \pm 6.2^{\mathrm{C}} & 6.7 \pm 0.6^{\mathrm{C}} & 19.9 \pm 6.5^{\mathrm{C}} \\ \text { A } & +/+ & \text { A6G2 } & 103.7 \pm 8.7^{\mathrm{B}} & 2.7 \pm 1.4^{\mathrm{A}} & 10.0 \pm 0.5^{\mathrm{B}}\end{array}$

AHR was measured using the noninvasive head-out-body plethysmography method in response to methacholine (see Supplemental Methods). Groups include mice reconstituted with nonallergic (NA) or asthmatic (A) PBMCs. The antibody-treated groups were compared with the positive control (SCID mice reconstituted with asthmatic PBMCs, allergen-sensitized and challenged, and treated with PBS). For AHR and BAL leukocytes, the statistical significance between negative control (SCID mice reconstituted with nonallergic PBMCs, allergen sensitized and challenged, and treated with PBS) and positive control was $P<0.05$. ${ }^{A} P<0.05$; ${ }^{B} P<0.01$; ${ }^{C}$ not significant. ND, not determined. Each value represents the mean \pm SEM of $6-8$ animals per group. Results represent 1 of 3 independent experiments.

activation by DCs critically depends on TIM-1 signaling. These data suggest that human TIM-1 antagonism by mAb A6G2 was able to substantially block myeloid DC-dependant Th2 T cell activation.

\section{Discussion}

TIM1 has been identified as a gene associated with asthma and other diseases in multiple human genetic studies (3). All TIM family proteins are type I cell surface glycoproteins and share common structural motifs, but protein interactions are complex in the TIM family. TIM-1 and TIM-4 appear capable of cationdependent homophilic and heterophilic interactions utilizing the BED face of the molecule, whereas TIM-2 dimerizes through interaction of $\mathrm{BC}$ and $\mathrm{CC}^{\prime}$ loop residues, with residues in the FG loop and $\mathrm{G} \beta$ strand (30). The difference in binding modalities may relate to the length of the $\mathrm{CC}^{\prime}$ loop found in TIM-2 versus TIM-1 or TIM-4 (30) and may also involve differential use of glycosylation sites. TIM-3 uses $\mathrm{N}$ - and O-linked glycosylation sites on the BED face and adjacent strands to bind its ligand galectin- 9 (31). TIM-3 homodimerization and heterodimerization with other family members has also been reported (26).

The IgV domain in all TIM proteins presents a unique cleft created by the $\mathrm{CC}^{\prime} / \mathrm{FG}$ configuration $(12,13)$. To date, the only ligand interaction ascribed to this cleft is the cation-dependent binding of TIM-1 and TIM-4 to PS $(13,24,25)$ and perhaps other phospholipids (32). Recently TIM-3 has also been described as having PS binding capability (33). TIM-1 and TIM-4, but not TIM-3, have a sialic acid-like binding motif that might regulate cleft structure through carbohydrate interaction, either on the mucin or stalk domains (having $\mathrm{O}$ - and $\mathrm{N}$-linked glycosylation sites, respectively) or to carbohydrate on another ligand. This sialic acid binding site includes amino acids at the top of the CC'/FG cleft (26). Whether the TIM-1 sialic acid binding motif mediates binding to carbohydrates in a manner that regulates cleft structure is not known. Mutations within the metal ion-dependant ligand binding site (MILBS) at the base of the cleft eliminate PS binding (13). The requirement for cation is confirmed by the observation that chelation with EDTA or EGTA dramatically reduces PS binding.

Interestingly, the observation that TIM-1 protein exhibits both cation-sensitive and cation-insensitive binding to DCs suggests that a novel mode of interaction with DCs may exist (26), as chelation of cations should significantly reduce or eliminate both
TIM-1/TIM-4 and TIM-1/PS binding $(13,26)$. In our study, the cation-insensitive binding of TIM-1 to cultured murine myeloid DCs (Figure 2A and Table 3 ) and freshly obtained murine CD $11 \mathrm{c}^{+}$ DCs (data not shown) was blocked by anti-mouse TIM-1 mAb $4 \mathrm{~A} 2$, a $\mathrm{mAb}$ that binds within the $\mathrm{F}>\mathrm{G}$ region, suggesting that multiple binding interactions may be mediated by this structure. In this regard it is important to first consider the potential for homophilic and heterophilic interactions. TIM-1 homophilic interaction utilizes the BED face of the protein (12) and not the $\mathrm{CC}^{\prime} / \mathrm{FG}$ face, and TIM-1/TIM-4 heterophilic interaction is likely to be similar. Furthermore, such an interaction would not be blocked by an antibody directed to the $\mathrm{F}>\mathrm{G}$ portion of the TIM-1 protein. TIM1 mRNA can be detected by RT-PCR in mouse and human DC populations, although protein expression has not been demonstrated (our unpublished observation). Of note, human TIM1 mRNA was detected in asthmatic and nonallergic PBMC preparations, but expression was not affected by disease state (Figure 6, C and D). Additionally, TIM4 mRNA is reportedly absent from mouse bone marrow-derived myeloid DCs (24, 25 ) and from human PBMC preparations (24), which represent 2 sources of the DCs used in our assays. We have previously shown that anti-murine mAb 4A2 antagonizes TIM-1 function in vivo, providing therapeutic benefit in a murine model of experimental asthma by modulating $\mathrm{T}$ cell function (9). We hypothesized that antagonism of the cation-insensitive TIM-1/DC binding using similar mAbs directed against human TIM-1 would be a functionally relevant activity assay. Screening mouse anti-human TIM-1 mAbs revealed that anti-human TIM-1 mAb A6G2 was sensitive to replacement of the human $F>G$ strand/loop with murine sequence and was efficiently able to block the binding of TIM-1-Fc to DCs in FACS assays. Furthermore, anti-human TIM-1 mAb A6G2 also greatly reduced binding of human TIM-1-Fc protein to activated human myeloid DCs or freshly obtained human CD $11 c^{+}$DCs in the presence of EGTA (Figures 2 and 3), just as anti-mouse TIM-1 mAb 4A2 did in the murine system. Most other anti-TIM-1 mAbs tested lacked such activity (Tables 2 and 3). On the basis of its activity in the DC binding assay, anti-human TIM-1 $\mathrm{mAb}$ A6G2 was chosen for further analysis in vivo and in vitro. We also examined the functional activity of anti-human TIM-1 mAb A3H1, which bound to the TIM-1 IgV domain with similar affinity as A6G2, but did not block binding to DCs. 

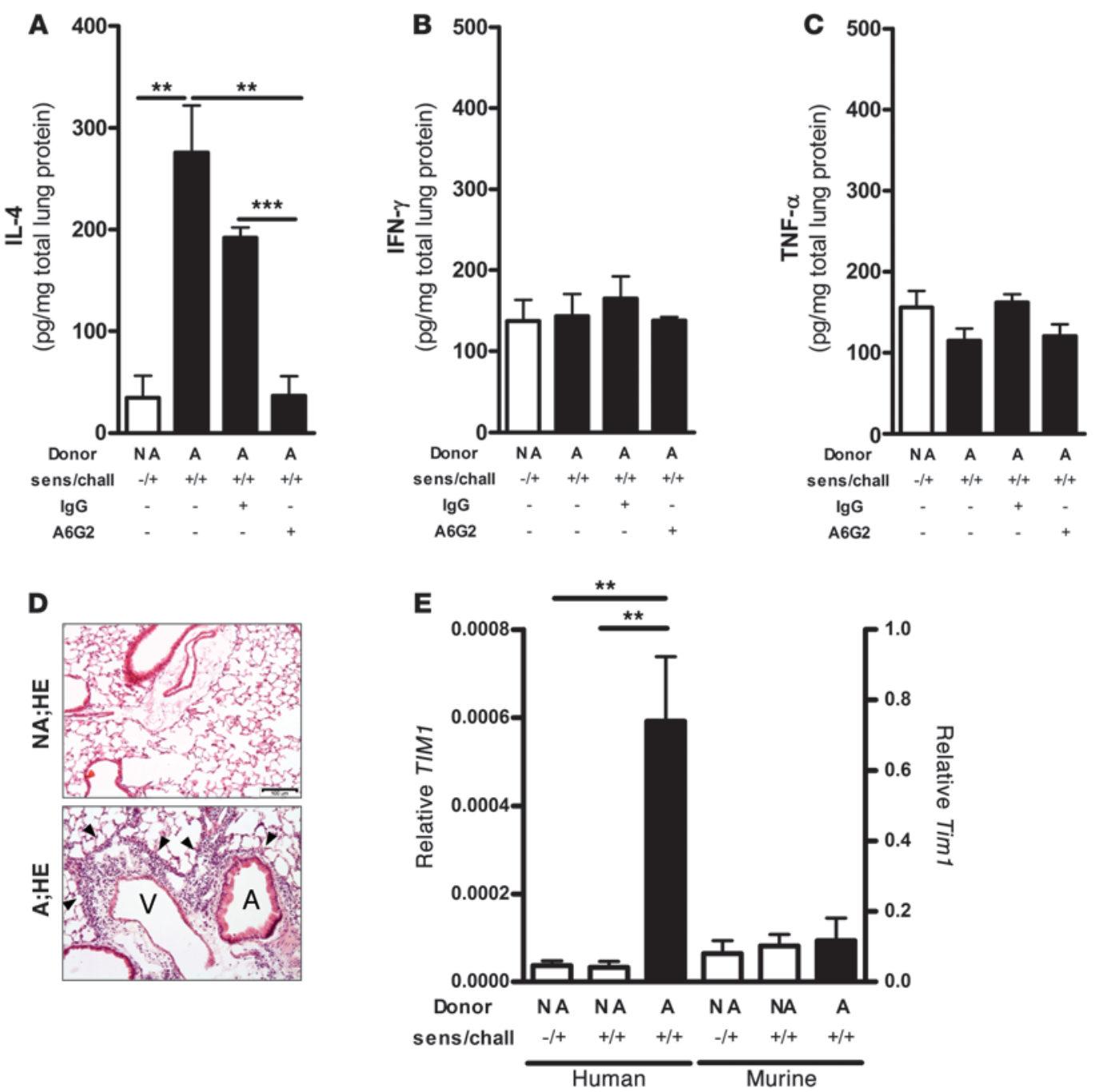

Figure 5

Analysis of human cytokines, TIM1 expression, and inflammation in lung tissue from hu-PBMC SCID mice. (A-C) IL-4 (A), IFN- $\gamma$ (B), and TNF- $\alpha$ (C) levels are presented as $\mathrm{pg} / \mathrm{mg}$ total lung protein as measured in lung homogenates. All measurements included mice receiving nonallergic (NA) donor PBMCs (white bar), asthmatic (A) donor PBMCs alone or with IgG control antibodies, or anti-human TIM-1 mAb A6G2. (D) Histological evaluation using $\mathrm{H} \& \mathrm{E}$ staining of inflammation in the lungs of mice receiving cells from nonallergic and asthmatic donors showing infiltration of mononuclear cells (arrowheads) around vessels (V) and airways (A). Scale bar: $100 \mu \mathrm{m}$. (E) Human (left $y$ axis) and murine (right $y$ axis) TIM1 mRNA analyzed in lung tissue of hu-PBMC SCID mice by qPCR. Scale represents TIM1 mRNA relative to human/murine L32. Mice were reconstituted with nonallergic or asthmatic donor PBMCs. Results represent 1 of 3 independent experiments comprising a cumulative total of $n=22$ asthmatic and $n=15$ nonallergic donors. Each experiment included $6-8$ animals per group that received PBMCs from at least 5 asthmatic or nonallergic donors. Values represent mean \pm SEM. Sens/chall, sensitization and challenge. ${ }^{* *} P<0.01 ;{ }^{* *} P<0.001$.

The therapeutic efficacy of human TIM-1 mAb A6G2 was tested in the hu-PBMC SCID model of T cell-dependent experimental asthma $(22,23)$. SCID mice were reconstituted with asthmatic PBMCs from patients with high $D$. pteronyssinus IgE titers, then challenged with $D$. pteronyssinus to trigger inflammation, cytokine production, and AHR. The development of asthma in this model led to the upregulation of human TIM1 mRNA in the lungs along with the induction of Th2 cell-associated transcription factors GATA- 3 and cMAF and the cytokine IL-4 (Figure 5, A and E, and Figure 7, A and B). Since these human TIM-1 primers did not detect mouse TIM-1, these data indicate expression of human TIM-1 in the inflammatory cells in the lung. Interestingly, mouse TIM-1 was expressed in lung tissue at lower levels than induced human
TIM-1, and expression of murine TIM-1 in the SCID mouse lung was not affected by the human inflammatory infiltrate in response to the asthmatic challenge protocol.

Similar to the therapeutic benefit seen in the murine OVA-induced asthma model with anti-murine TIM- $1 \mathrm{mAb} 4 \mathrm{~A} 2$, treatment of asthmatic hu-PBMC SCID mice with the anti-human TIM-1 mAb A6G2 strongly reduced BALF and tissue levels of the Th2 cytokine IL-4, reduced lung inflammation, and prevented AHR (Figure 5 and Table 5). These effects resulted from a suppression of the Th2 response rather than an induction of the Th1 response, since neither neutrophil numbers nor IFN- $\gamma$ levels were increased in the lungs of treated mice. As a positive control for the in vivo model, we chose anti-human IL-13 mAb treatment, a therapeutic 

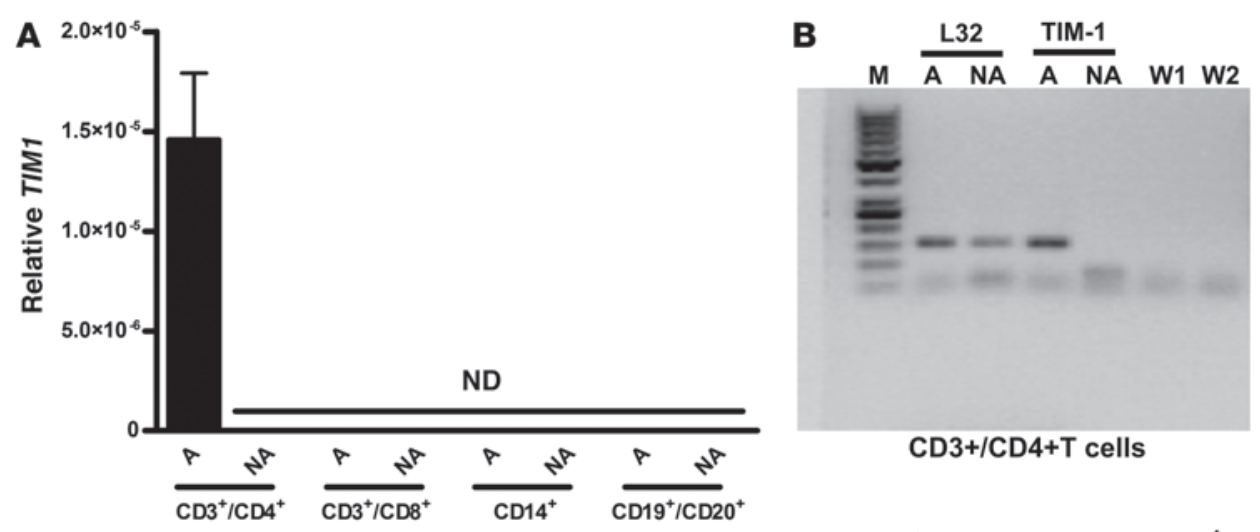

C

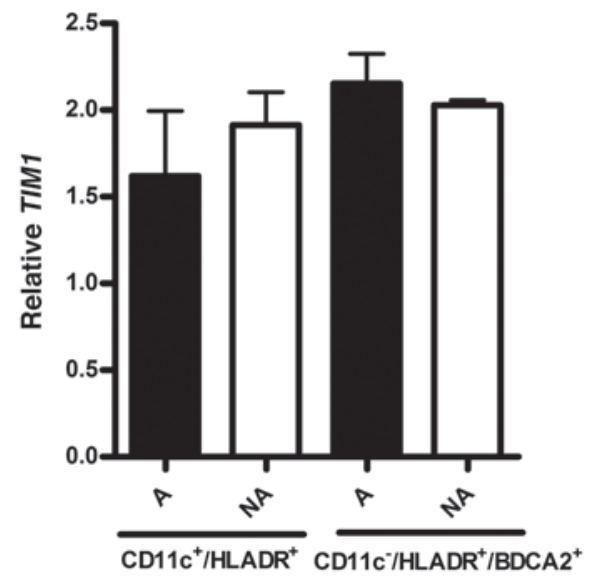

D

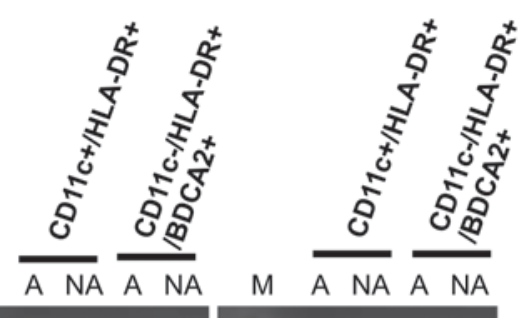

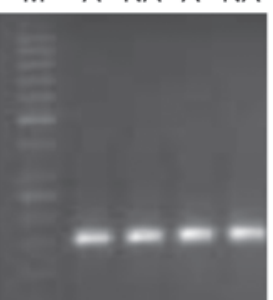

L32

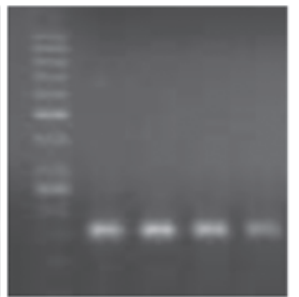

TIM-1

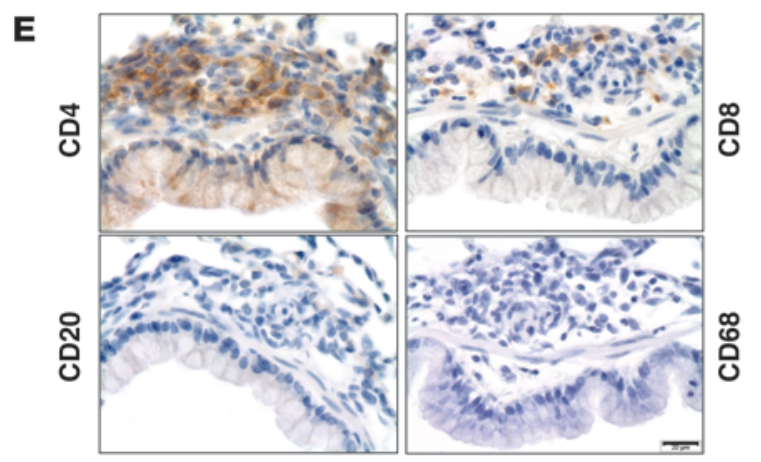

\section{Figure 6}

Cellularity and the expression of human TIM-1. (A) qPCR analysis of TIM1 mRNA in CD3 ${ }^{+} / \mathrm{CD} 4^{+} \mathrm{T}_{\text {cells, }} \mathrm{CD} 3^{+} / \mathrm{CD}^{+} \mathrm{T}$ cells, CD14+ ${ }^{+}$monocytes, and CD19+/CD20 + B cells from asthmatic and nonallergic PBMCs. Results represent 1 of 3 independent experiments including 4 asthmatic and nonallergic donors per group. ND, not detectible. (B) Image of a representative gel showing a 50-bp marker (M), L32, and human TIM-1 signal in asthmatic and nonallergic $\mathrm{CD} 3^{+} / \mathrm{CD} 4^{+} \mathrm{T}$ cells. W1 and W2 were water controls for L32 and TIM-1 primers, respectively. (C) qPCR analysis of L32 and human TIM1 mRNA in CD11 $+/ \mathrm{HLA}^{-D R+}$ DCs and CD11c-/HLA-DR+/BDCA-2+ DCs from asthmatic (black bars) and nonallergic (white bars) individuals. Results represent 1 of 3 independent experiments including 4 asthmatic and nonallergic donors per group. (D) Image of a representative gel showing 50-bp markers (M), L32, and human TIM-1 signals in asthmatic and nonallergic CD11 $\mathrm{C}^{+} / \mathrm{HLA}^{-D R^{+}} \mathrm{DC}$ and

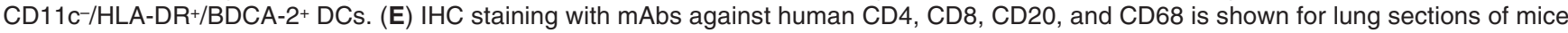
receiving PBMCs from asthmatic donors. No positive staining for CD4, CD8, CD20, or CD68 was found in the nonallergic group (data not shown). Scale bar: $20 \mu \mathrm{m}$. Nonallergic and asthmatic groups received $4 \times 10^{7}$ nonallergic or asthmatic PBMCs, respectively, and were exposed to $D$. pteronyssinus as described in Methods. Pictures are representative of 2 animals from each group.

modality known reduce Th2-dependent allergic asthma responses and currently being evaluated in human clinical trials $(34,35)$. Notably, anti-human TIM-1 mAb A6G2 treatment resulted in even stronger therapeutic benefit than anti-IL-13 mAb treatment in this model. Furthermore, we detected a decrease in lung GATA3 and $c M A F$ mRNA and IL-4 protein in BALF. Interestingly, antihuman TIM-1 mAb A6G2 treatment led to an increase in Foxp3 mRNA levels, a result which corroborates a recent report that 

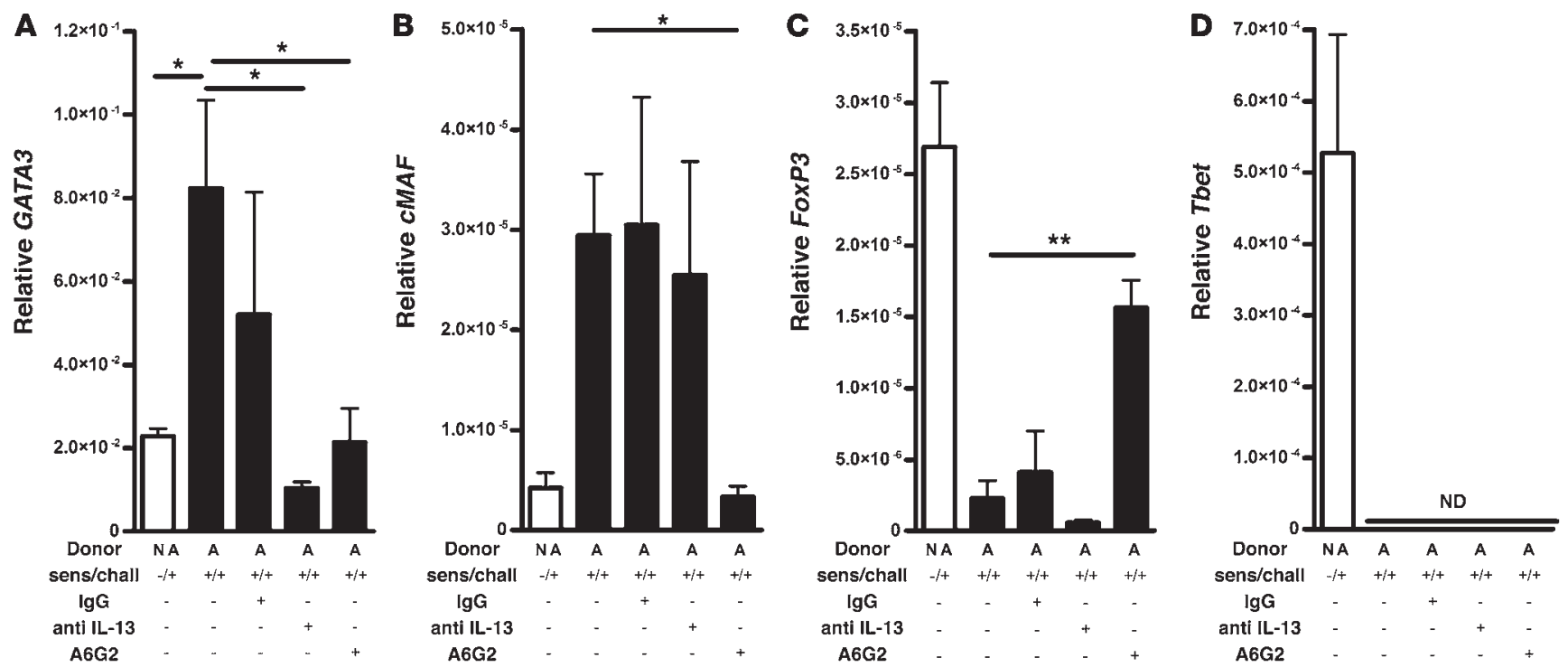

E

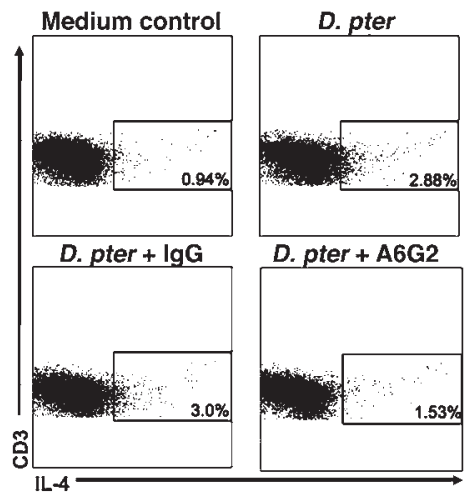

$\mathbf{F}$

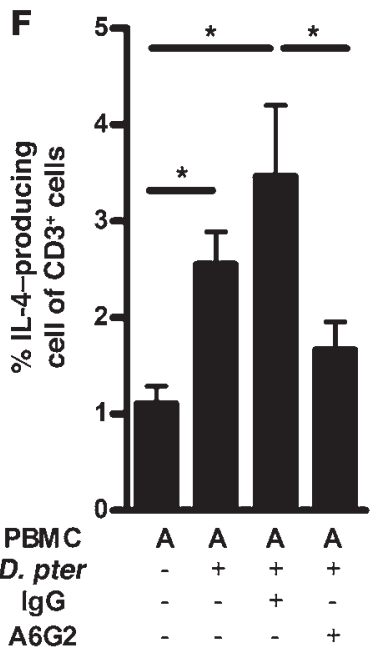

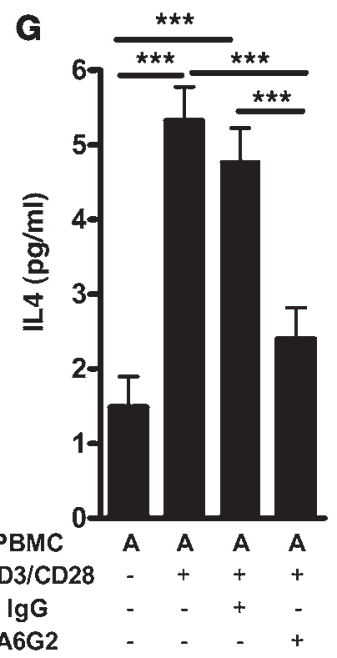

H

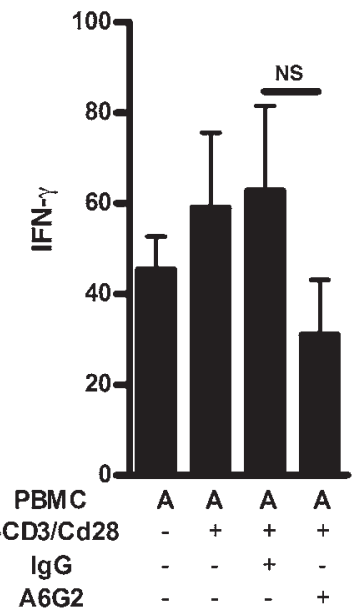

I

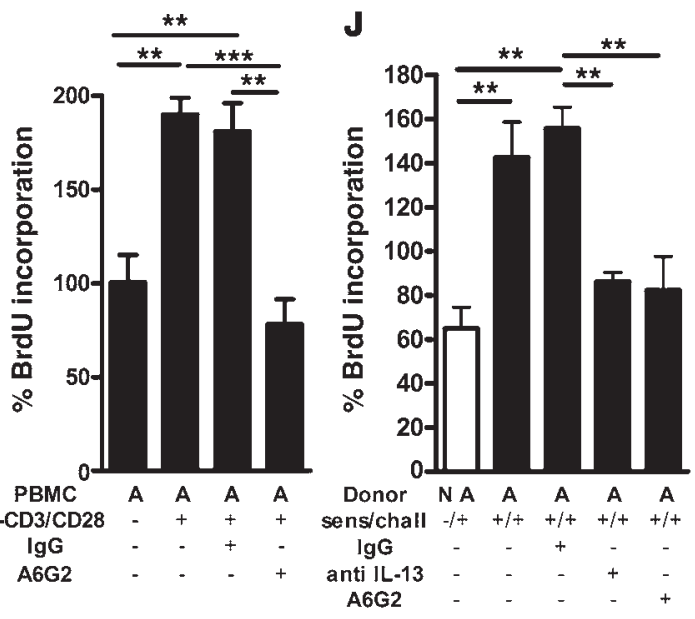

$\mathbf{K}$

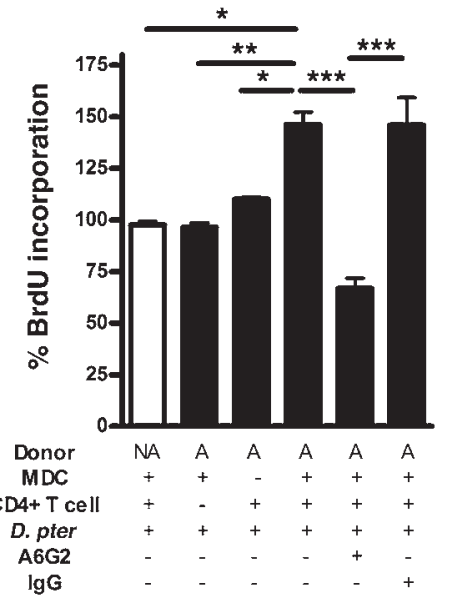

$\mathbf{L}$

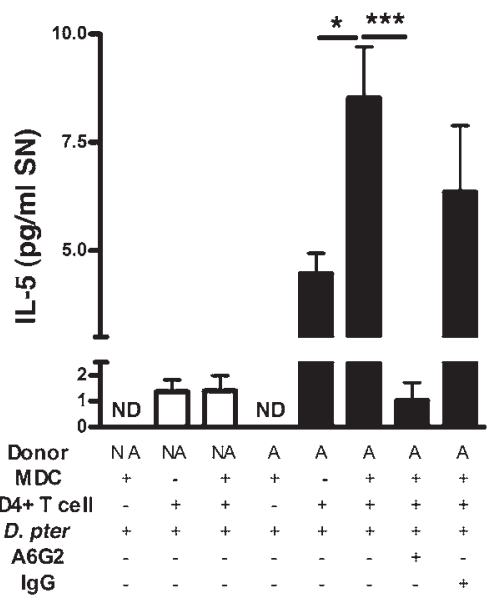




\section{Figure 7}

Mechanism of TIM-1 antagonism. Nonallergic control (white bars) or asthmatic (black bars) donor samples are indicated as appropriate. (A-D) qPCR of GATA3, CMAF, FoxP3, and Tbet in lung tissue. (E) FACS analysis of IL-4+/CD3 ${ }^{+} \mathrm{T}$ cells from control or $D$. pteronyssinus-stimulated asthmatic donor PBMCs, incubated with mAbs as indicated. (F) Percentage of IL-4-expressing $\mathrm{CD}^{+} \mathrm{T}$ cells in all groups. ( $\mathbf{G}$ and $\mathbf{H}$ ) Human IL-4 and IFN- $\gamma$ levels from asthmatic human PBMC supernatants. (I and J) Proliferation of human PBMCs and hu-PBMC SCID splenic mononuclear cells measured as percent BrdU (percent normalized to unstimulated control). ( $K$ and $\mathbf{L}$ ) Activated $C D 4^{+} T$ cell proliferation and IL-5 production after coculture with $D$. pteronyssinus plus autologous myeloid DCs from nonallergic control and asthmatic donors. In vivo experiments (A-D and $\mathbf{J}$ ) included nonallergic donor controls and asthmatic donors, alone or treated with $\mathrm{mAb}$ as indicated, and represent 3 independent experiments. In vitro analyses $(\mathbf{E}-\mathbf{I})$ included an unstimulated asthmatic PBMC control, D. pteronyssinus, or anti-CD3/anti-CD28stimulated asthmatic PBMCs alone or incubated with mAb. (K-L) Groups for in vitro analysis included nonallergic or asthmatic myeloid DCs plus $\mathrm{CD}^{+} \mathrm{T}$ cells stimulated with $D$. pteronyssinus with or without $\mathrm{mAb}$; other controls included only nonallergic myeloid DCs or $\mathrm{CD}^{+}$cells stimulated with $D$. pteronyssinus. In vitro data represent 3 independent experiments comprising 4 asthmatic and 4 nonallergic donors per group. Values represent mean \pm SEM. ${ }^{\star} P<0.05 ;{ }^{\star \star} P<0.01 ;{ }^{* \star \star} P<0.001$.

agonist anti-TIM-1 mAb caused downregulation of FoxP3 (36). However, we did not detect an increase in the number of FoxP3 ${ }^{+}$ cells in the lung, suggesting that the effect of human TIM-1 antagonism was due to blockade of the Th2 response rather than an induction of Tregs. Nonetheless, these findings indicate a functional effect of TIM-1 antagonism in addition to modulation of Th2 cells that requires further investigation.

A number of reports demonstrate expression of murine TIM-1 on Th2 CD4 ${ }^{+} \mathrm{T}$ cells $(32)$ and B cells $(9,33)$. Expression of human TIM-1 has not been as conclusively demonstrated, with only a few studies showing expression on activated T cells (34) and kidney epithelium (37). As TIM1 mRNA was seen to be selectively expressed in CD4 ${ }^{+}$ $\mathrm{T}$ cells of asthmatic patients, the increase in human TIM1 mRNA in lungs of SCID mice is suggested to result from the subsequent expansion of $D$. pteronyssinus-specific T cells by antigen challenge. We postulate that the observed suppression of the Th2 phenotype was a direct effect of anti-human TIM-1 mAb A6G2 on T cells, rather than effects from bystander cells. However, we were not able to detect cell surface expression of TIM- 1 on T cells by FACS, perhaps indicating that cellcell contact, transient $\mathrm{Ca}^{++}$flux (12), or other signals are required to maintain expression. This issue requires further investigation.

Additional in vitro experiments showed that anti-human TIM-1 $\mathrm{mAb}$ A6G2 reduces the number of IL-4-producing $\mathrm{CD}^{+} \mathrm{T}$ cells, inhibits IL-4 production, and suppresses $\mathrm{T}$ cell proliferation in response to $D$. pteronyssinus stimulation (see Figure 7). Importantly, anti-human TIM-1 mAb A6G2 blocked the activation of alreadyprimed, $D$. pteronyssinus-specific T cells by DCs in vitro, which again suggests a direct effect on $\mathrm{T}$ cell activation and further suggests that it might be possible to directly target pathogenic memory $\mathrm{T}$ cells in vivo through antagonism of TIM-1.

The striking impact of anti-human TIM-1 mAb A6G2 on cytokine production, lung inflammation, and AHR is consistent with the observation that TIM-1 is genetically linked to human atopic disease $(38,39)$. The TIM1 gene is also associated with murine atopic immune responses (7), and anti-TIM-1 mAbs have been shown to affect murine allergic inflammation and other pathologies $(8,9,40,41)$. As shown here, anti-mouse TIM-1 mAb $4 \mathrm{~A} 2$ and anti-human TIM-1 mAb A6G2 both target the CC'/FG cleft of the IgV domain, and both have therapeutic activity in asthma models. This may be due to their ability to block TIM-1 binding to PS, DCs, or both. Interestingly, our analysis of RMT1-10, a second anti-mouse TIM-1 mAb with therapeutic activities (40, 41), showed that while RMT-10 was capable of blocking mouse TIM-1/DC binding, it did not affect PS binding (data not shown). These data suggest that the antagonism of the TIM-1/DC interaction is important for therapeutic effects, and our data suggest the existence of an additional, uncharacterized ligand on DCs. We propose that TIM-1 interaction with PS may serve an interrogatory function, by which $T$ cells monitor the health and integrity of cells with which they interact. Thus, healthy cells will express low levels of PS, generally bound up in cis cell surface interactions (24). In this regard the activity of agonist anti-TIM- $1 \mathrm{mAbs}$ described in the murine system $(9,36)$ is of particular interest, since such mAbs may recapitulate the pathway triggered by a non-PS ligand/TIM1 interaction. To our knowledge, such agonist anti-TIM-1 mAbs have not yet been described in the human system.

In summary, we have demonstrated that the antagonism of TIM-1 activity blocks the asthmatic response in a humanized mouse model, providing functional evidence to support the hypothesis that TIM-1 is genetically linked to human atopic disease (6). We have shown that modulation of TIM-1 signaling by blocking TIM-1 binding strongly inhibits T cell pro-proliferative and effector activities, which are critical for aggravation of allergic disease. Furthermore, we have outlined the structure/activity relationships that define therapeutic anti-human TIM- 1 mAbs using a comprehensive panel of biochemical and functional analyses. Such progress in our understanding of TIM-1 activity will support ongoing efforts to identify novel TIM-1 ligands and will guide future development of therapeutics for asthma and other diseases.

\section{Methods}

Cloning of expression constructs. Human TIM1 was PCR amplified from a kidney cDNA library using the oligonucleotide primers KID-309 (5'-TAGCGGCCGCAGGCTGATCCCATAATG-3') and KID-311 (5'-TAGCGGCCGCTTTCCAGGGACTATTCTC-3'), yielding the allelic variant with the 5-amino acid insertion at position 158 (MTTVP) described by McIntire et al. (7) and cloned NotI/NotI into vector pEAG347, a mammalian expression vector suitable for transient transfections, to create vector SJR102. The extracellular domain was subcloned in-frame with a human IgG1-Fc coding sequence to create PEM151, in vector pv90, an expression vector suitable for transient transfections or for selection in $\mathrm{CHO}$ cells. The human TIM1 IgV domain was PCR amplified from SJR102 using the oligonucleotide primers SC1-793 (5'-GCGGCCGCTCTAGAATGCATCCTCAAGTGGTCATCTT-3') and SC1-794 (5'-ACTAGTGTCGACGGGTGGCACAATCTCCAATGATA-3') and cloned in-frame with a human IgG1-Fc coding sequence into vector pv90, to create PEM112. Human TIM-1-Fc and TIM-1-IgV-Fc proteins were purified from cell culture supernatants using protein-A column chromatography and size exclusion chromatography to isolate a homogeneous preparation. Murine constructs and proteins were produced as previously described (9).

Generation and screening of monoclonal antibodies. RBF mice were immunized with full-length purified human TIM-1-Fc protein. The primary immunization was with $25 \mu \mathrm{g}$ protein in $25 \mu \mathrm{l}$ Protein A Sepharose beads (Amersham Biosciences) in one flank delivered s.c. and $25 \mu \mathrm{l} \mathrm{CFA/PBS} \mathrm{given} \mathrm{i.p.} \mathrm{The}$ second immunization was similar, except that IFA/PBS was used in place of CFA/PBS. Three days before fusion, $50 \mu \mathrm{g}$ protein in $50 \mu \mathrm{l}$ Protein A 
Sepharose beads was delivered s.c. along with $50 \mu 1 \mathrm{RIBI} / \mathrm{PBS}$ given i.p. Finally, 1 day before fusion, $50 \mu \mathrm{g}$ protein was given in PBS i.v. The spleen was harvested, and splenic B cells were fused to FL-653 myeloma cells. After limiting dilution, hybridoma clones were grown out and screened for $\mathrm{mAb}$ binding, in supernatant, to purified human TIM-1-IgV-Fc protein in a standard ELISA format. Positive clones were subcloned, expanded, and used for the generation of purified monoclonal antibodies using standard Protein A chromatographic techniques. All purified mAbs were checked by size exclusion chromatography for homogeneity and were assayed for endotoxin, which was routinely less than 0.05 endotoxin units per milligram. Rat anti-mouse TIM-1 mAbs were produced as described in ref. 9.

Anti-TIM-1 antibody characterization. EC 50 values for anti-human TIM-1 mAbs were determined by ELISA analysis. Briefly, ELISA plates (Corning Costar) were coated with $0.2 \mu \mathrm{g} / \mathrm{ml}$ human TIM-1-Fc overnight at $4^{\circ} \mathrm{C}$ and then blocked for 1 hour at $22^{\circ} \mathrm{C}$ with PBS/0.5\% casein. Plates were thoroughly washed with PBS/0.1\% Tween-20. Anti-human TIM-1 mAbs were added across a range of concentrations starting at $10 \mu \mathrm{g} / \mathrm{ml}$ and using $1: 3$ dilutions, all in PBS/ $0.5 \%$ casein, and allowed to incubate for 1 hour at $22^{\circ} \mathrm{C}$. The plates were washed again, and then a 1:1,000 dilution of HRPconjugated goat anti-mouse IgG $(\mathrm{H}+\mathrm{L}$; Jackson Immunoresearch Laboratories) was added in PBS $/ 0.5 \%$ casein for an additional hour at $22^{\circ} \mathrm{C}$. After a final wash, the plates were developed using substrate solution mix $(\mathrm{R} \& \mathrm{D}$ Systems) and stopped using $2 \mathrm{~N} \mathrm{H}_{2} \mathrm{SO}_{4}$. Plates were read at $450 \mathrm{nM}$ using a microplate reader and analyzed using SoftMax Pro (Molecular Devices). Relative $\mathrm{EC}_{50}$ values were determined from the binding curves. Rat antimurine TIM-1 mAbs were analyzed similarly using immobilized murine TIM-1 fusion proteins (9).

In order to determine the region within the $\operatorname{IgV}$ domain bound by anti-human TIM-1 mAb A6G2, a mutant molecule was made in which the $\mathrm{F}$ and $\mathrm{G}$ strands and intervening loop within the $\operatorname{IgV}$ domain of human TIM-1 were replaced by sequence from mouse TIM-1. Fulllength human TIM-1 was cloned into a pNE001-derived EBV expression vector to create pEAG2182. pEAG2182 was subjected to site-directed mutagenesis (QuikChange; Stratagene) to mutate the human F strand/ loop sequence to the mouse sequence using oligonucleotides KM1-685 (5'-GCTGTGTCTGACAGTGGCCTATATTGTTGCCGTGTTGAGATCCCTGGGTGGTTCAATGACATG-3') and KM-686 (5'-CATGTCATTGAACCACCCAGGGATCTCAACACGGCAACAATATAGGCCACTGTCAGACACAGC-3') to create pEAG2193. pEAG2193 was further mutagenized to replace the rest of the F > G loop and G strand using oligonucleotide primers KM1-687 (5'-CCTGGGTGGTTCAATGACCAGAAG GTCACCTTTTCATTGCAAGTTAAACCACCTAAGGTCACGACTAC-3') and KM1-688 (5'-GTAGTCGTGACCTTAGGTGGTTTAACTTGCAATGAAAAGGTGACCTTCTGGTCATTGAACCACCCAGG-3') to create pEAG2198. Mutated and wild-type constructs were used to transfect 293 cells, along with an EGFP expression plasmid.

FACS analysis of transfected cells. For analysis of $\mathrm{mAb}$ binding to mutated forms of human TIM-1, 293 cells were grown to approximately $80 \%$ confluence in DMEM/10\% FBS, then transfected using Effectene, following the manufacturer's instructions (Qiagen). EGFP expressing plasmid was cotransfected with the TIM-1-expressing plasmids. After 48 hours, cells were washed and harvested into PBS $/ 0.5 \% \mathrm{BSA} / 0.1 \%$ sodium azide for FACS analysis. Mouse anti-human TIM-1 mAbs or isotype control were added for 1 hour on ice, the cells were washed with PBS, then fluorescently labeled goat anti-human IgG-Fc antisera was added for an additional hour, before a final washing and fixation in PBS/1\% paraformaldehyde. EGFP-positive cells were gated to ensure that only transfected cells were analyzed. FACS data were collected on a FACSCaliber Instrument (BD Biosciences) and analyzed using FloJo software after gating on the EGFP-positive cell population.
Effect of anti-TIM-1 mAbs on TIM-1 binding to phosphatidylserine. Plates (96-well; Corning Costar 3590) were coated with $10 \mu \mathrm{g} / \mathrm{ml}$ PS in $100 \mu \mathrm{l}$ methanol and placed in an exhaust hood until dry, then blocked with $200 \mu \mathrm{l} /$ well of $1 \%$ BSA in Tris buffer (25 mM Tris, $137 \mathrm{mM} \mathrm{NaCl}, \mathrm{pH} 7.2)$ for 1 hour. Wells were washed 4 times with $0.05 \%$ Tween-20 in Tris buffer. Murine TIM-1-Fc or human TIM-1-Fc proteins in $100 \mu \mathrm{l}$ \% BSA/Tris were bound for 1 hour to PS-coated plates across a range of concentrations using 1:3 dilutions starting from $100 \mu \mathrm{g} / \mathrm{ml}$. After 3 washes with $0.05 \%$ Tween-20/Tris buffer, $100 \mu \mathrm{l} /$ well of a 1:1,000 dilution of HRP-conjugated goat anti-human IgG-Fc antibody (Jackson Immunoresearch Laboratories) in 1\% BSA/Tris was added for 1 hour. Following 4 additional washes with $0.05 \%$ Tween-20/Tris, the plates were developed using $50 \mu \mathrm{l} /$ well substrate solution (R\&D Systems) then stopped by adding $100 \mu \mathrm{l} 2 \mathrm{~N} \mathrm{H}_{2} \mathrm{SO}_{4}$. Plates were read on a microplate reader at $450 \mathrm{nM}$. We determined the dependence of PS/TIM-1 binding on the presence of cation by using Tris buffer without additional $\mathrm{Ca}^{++} \mathrm{Or} \mathrm{Mg}^{++}$added, or by adding $1 \mathrm{mM}$ EGTA to the binding solution. Anti-mouse TIM- 1 or antihuman TIM-1 mAbs were used to compete for binding to PS in Tris buffer containing $1 \mathrm{mM} \mathrm{Ca}^{++}$and $1 \mathrm{mM} \mathrm{Mg}^{++}$at a concentration of $10 \mu \mathrm{g} / \mathrm{ml}$.

Effect of anti-TIM-1 mAbs on TIM-1 binding to DCs. Mouse DCs were cultured from bone marrow to yield myeloid DCs, as previously described (42), or were analyzed as $\mathrm{CD} 11 \mathrm{c}^{+}$DCs from splenocyte preparations. Human myeloid DCs were cultured from $\mathrm{CD} 34^{+}$stem cells as instructed by the supplier (Stem Cell Technologies) or were analyzed as CD11 $\mathrm{c}^{+}$DCs from PBMC preparations. Anti-mouse $\mathrm{CD} 11 \mathrm{c} \mathrm{mAb}$ and anti-human $\mathrm{CD} 11 \mathrm{c}$ mAb were purchased (BD Biosciences) for use in assessing purity (routinely > 90\%) and for gating cell populations. In some experiments DCs were stimulated with $100 \mathrm{ng} / \mathrm{ml}$ LPS (Sigma-Aldrich) for 48 hours. TIM-1-Fc fusion proteins were incubated with cell samples at various concentrations for 1 hour on ice, in the presence or absence of $1 \mathrm{mM}$ EGTA, and in the presence or absence of $10 \mu \mathrm{g} / \mathrm{ml}$ anti-TIM-1 mAbs or isotype control mAbs (rat IgG2a [BD Biosciences] and mouse mAb MOPC21 [ATCC]). TIM-1-Fc fusion protein binding was analyzed by FACS after incubation using fluorochrome-conjugated goat anti-human IgG-Fc (Jackson Immunoresearch Laboratories). Cells were fixed in $1 \%$ paraformaldehyde immediately after staining.

SCID mice. Female SCID mice (6-8 weeks old; C.B-17 SCID) were obtained from Harlan Winkelmann (Borchen) and maintained under pathogen-free conditions. All animal experiments were performed according to The guidelines for the care and use of experimental animals prepared by the Society for Laboratory Animal Sciences (GV-SOLAS), performed in accordance with German law under "Genehmigung von Versuchsvorhaben V 54 - 19 c 20-15 (1) MR20/13-Nr.75/2007," and was approved by the Regierungspra_sidium Gießen, the regional ethics committee responsible for the University of Marburg, Marburg, Germany.

Donors and preparation of donor PBMCs. Asthmatic patients sensitized to house dust mite allergen (D. pteronyssinus) were identified by elevated serum D. pteronyssinus-specific IgE antibody titers. Human serum IgE antibody titers were measured by fluorescence enzyme immunoassay (Pharmacia CAP System; Pharmacia). A total of 22 allergic and asthmatic patients suffering from moderate to severe asthma according to international guidelines (Global Initiative for Asthma) with antibody titers of at least $410 \mathrm{ng} / \mathrm{ml}$ for total $\mathrm{IgE}$ and at least $20 \mathrm{ng} / \mathrm{ml}$ for anti-D. pteronyssinus IgE antibodies were selected as donors and referred to as asthmatics. A total of 15 nonallergic healthy subjects with total serum IgE concentrations of less than $17 \mathrm{ng} / \mathrm{ml}$ and antiD. pteronyssinus $\mathrm{IgE}$ of less than $0.8 \mathrm{ng} / \mathrm{ml}$ were referred to as nonallergic donors. All blood samples were obtained with written informed consent. Heparinized blood (200-250 ml) was collected from asthmatic and nonallergic donors, and mononuclear cells were purified by Histopaque (SigmaAldrich) density gradient centrifugation. The human donor PMC-collection was approved by the ethics committee of Graubunden, Switzerland, responsible for the Hochgebirgsasthmaklinik, Davos, Switzerland. 
Table 6

Primers for qPCR

\begin{tabular}{lll} 
Gene & \multicolumn{1}{c}{ Sense } & \multicolumn{1}{c}{ Antisense } \\
L32 & AGTTCCTGGTCCACAACGTC & TTGGGGTTGGTGACTCTGAT \\
TIM1 & CTGCAGGGAGCAATAAGGAG & TCCAAAGGCCATCTGAAGAC \\
Tim1 & CTATGTTGGCATCTGCATCG & AAGGCAACACGCTTAGAGA \\
GATA3 & ACAGAAGGCAGGGAGTGTGT & GTCTGACAGTTGGCACAGGA \\
Thet & GCTGTCACCACTGGAAGGAT & TTGGTGTGGACTGAGATTGC \\
Foxp3 & TCCCAAATCCCAGTGCACCCAG & TCACATCCGGGCCACTTGC \\
Cmaf & GGACGCGTACAAGGAGAAAT & G CTTCCAAAATGTGGCGTAT \\
Rorgt & GAGGAAGTCCATGTGGGAGA & TCCTAACCAGCACCACTTCC \\
Rora & GACATACAGCCTTCCCAGA & CACAATTGCCACATCACCTC
\end{tabular}

The $L 32$ primer set was reactive with both human and murine L32. Primers for human TIM-1 (TIM1) and murine TIM-1 (Tim1) were species specific.

Reconstitution of SCID mice with donor PBMC. Three independent experiments were performed. Each experiment included 6-8 animals per group that received PBMCs from at least 5 asthmatic or nonallergic donors. SCID mice received $2 \times 10^{7}$ PBMCs i.p. on day 1 . Mice also received $100 \mu \mathrm{g}$ of purified house dust mite extract (Allergopharma Joachim Ganzer), referred to as $D$. pteronyssinus, with $14 \mathrm{mg} / \mathrm{ml}$ of aluminium hydroxide adjuvant (Pierce Biotechnology) on the same day as the cell transfer and on days 7 and 14. All animals were aerosol challenged with $200 \mu \mathrm{g} D$. pteronyssinus diluted in $5 \mathrm{ml}$ PBS for 20 minutes on days 16, 18, 20, 23, and 25. Animals also received $100 \mu \mathrm{g}$ i.p. injections of control IgG1 antibody (MOPC21), anti-human IL-13, anti-human TIM-1 mAb A6G2, or anti-human TIM-1 $\mathrm{mAb}$ A3H1 diluted in $200 \mu \mathrm{l} \mathrm{PBS}$, or PBS alone (Figure 4, A and B).

Evaluation of human and murine TIM-1 expression, GATA-3, T-bet, FoxP3, $C M A F, R O R \gamma t$, and ROR $\alpha$ expression in the lungs of hu-PBMC SCID mice. Lung tissue was harvested, and snap-frozen tissue was processed for RNA extraction using the RNeasy protocol (Qiagen). Contaminating genomic DNA was removed by DNase treatment using the DNA-free kit (Ambion), and cDNA synthesis was performed with $500 \mathrm{ng}$ of total RNA using the SuperScript III Reverse Transcriptase (Invitrogen). qPCR was performed using the QuantiTect SYBR Green PCR Kit (Qiagen). Primers specific for human and murine TIM-1 and human GATA-3, T-bet, FoxP3, cMAF, ROR $\gamma$ t, and ROR $\alpha$ are described in Table 6 . The mRNA copy numbers were normalized and expressed relative to the human/mouse ribosomal L32 as the housekeeping gene. Following an initial denaturation step of 15 minutes at $95^{\circ} \mathrm{C}, 45$ PCR cycles of $94^{\circ} \mathrm{C}$ for 15 seconds, $60^{\circ} \mathrm{C}$ for 30 seconds, and $72^{\circ} \mathrm{C}$ for 15 seconds were performed. Finally, product homogeneity was verified by melting curve analysis. Real-time qPCR analysis was performed using a Light-Cycler System (Roche). All standard procedures were performed as per the manufacturer's instructions.

Assessment of AHR. Noninvasive measurement of mid-expiratory airflow $\left(\mathrm{EF}_{50}\right)$ to methacholine was measured 24 hours after the last $D$. pteronyssinus aerosol challenge using head-out body plethysmography as described previously (43). Dose-response curves of airway reactivity to methacholine was assessed using head-out body plethysmography (see Supplemental Methods).

$B A L F$ and cellular analyses. Forty-eight hours after the last allergen challenge, BALF was collected and analyzed as previously described (44). The total number of leukocytes was determined by using a Casy TT cell counter (Schaerfe Systems). Cells were differentially stained with DiffQuick (DADE Diagnostics).

Measurement of human cytokines. Human IL-4 (BenderMed) with a detection limit of $0.25 \mathrm{pg} / \mathrm{ml}$ and IFN- $\gamma$ (OptEIA; BD Biosciences) with a detection limit of $4.7 \mathrm{pg} / \mathrm{ml}$ were measured in the cell-free lavage fluid or cell culture according to the manufacturer's instructions. For detection of human cytokines in lung homogenates, snap-frozen lungs were thawed, weighed, crushed, and homogenized in $500 \mu \mathrm{l}$ of T-PER (Thermo Scientific) containing Complete Mini Protease Inhibitor Cocktail tablets (Roche; 1 tablet/10 $\mathrm{ml}$ of T-PER stock reagent). Lung homogenates were centrifuged at 9,000 $\mathrm{g}$ for 10 minutes at $4{ }^{\circ} \mathrm{C}$. Total protein concentrations in supernatants were determined using a BCA kit (Thermo Scientific), and human Cytokine 11-Plex kit reagents were used to evaluate amounts of IL-1 $\beta,-2,-4$, $5,-6,-8,-10$, and -12 (p70), TNF- $\alpha$, TNF- $\beta$, and IFN- $\gamma$ expression patterns (BenderMed). Specific cytokine protein concentrations were expressed as $\mathrm{pg} / \mathrm{mg}$ total lung protein.

Cell culture assay. Mononuclear cells were purified by Histopaque (Sigma-Aldrich) density gradient centrifugation. PBMCs $\left(1 \times 10^{6} / \mathrm{ml}\right)$ were either stimulated with $D$. pteronyssinus $(500 \mathrm{ng} / \mathrm{ml})$ for 72 hours for staining IL-4-positive CD3 cells by FACS or incubated with $\mathrm{mAb}$ CD3/CD28-coated plates (BD Biosciences) at a concentration of $500 \mathrm{ng} / \mathrm{ml}$ and $1 \mu \mathrm{g} / \mathrm{ml}$ respectively for 24-48 hours. Cells were grown in medium alone or with anti-human TIM-1 mAb A6G2 $(1 \mu \mathrm{g} / \mathrm{ml})$ or control IgG $(1 \mu \mathrm{g} / \mathrm{ml})$. The supernatants were further processed for cytokine analysis.

Cell preparation and FACS analysis. Histopaque-purified PBMCs were resuspended in PBS, stained with fluorochrome-labeled mAbs, and sorted with the MoFlo flow cytometer (DakoCytomation). For the sorting procedure, cells were gated with a combined live gate, according to scatter characteristics and dead cell exclusion via DAPI stain at $100 \mathrm{ng} / \mathrm{ml}$ final concentration (Sigma-Aldrich). T cells were discriminated using CD3 and CD4 or CD8 antibody surface staining, monocytes using CD 45 and CD14 staining, B cells using CD19 and CD20 staining (BD Biosciences), myeloid DCs using CD11c and HLA-DR, and plasmacytoid DCs using HLA-DR and BDCA-2 (BD Biosciences). Sorting was performed in 1.5 -ml plastic tubes at room temperature without external cooling. The sort purity was greater than $95 \%$.

Myeloid DC/T cell culture. CD $14^{+}$and $\mathrm{CD}^{+} \mathrm{T}$ cells were isolated from asthmatic and nonallergic donors using whole blood CD14 and CD4 MicroBeads (Miltenyi Bitotech). $\mathrm{CD}^{+}$and $\mathrm{CD} 14^{+}$cells were isolated directly from whole blood using automated magnetic cell sorting (autoMACS Magnetic Cell Sorting; Miltenyi Bitotech). Isolated CD14+ cells were cultured in RPMI complete medium with $100 \mathrm{ng} / \mathrm{ml}$ of GM-CSF and IL-4 (Miltenyi Bitotech) at $37^{\circ} \mathrm{C}$ in $5 \% \mathrm{CO}_{2}$ for 6 days. DCs were checked for differentiation and maturation markers CD83, CD86, and HLA DR (BD Biosciences) before coculture with $\mathrm{T}$ cells. Purified autologous $\mathrm{CD} 4^{+} \mathrm{T}$ cells were isolated (Miltenyi Bitotech) and were co-cultured with myeloid DCs at a 1:10 ratio in complete medium with or without $D$. pteronyssinus, $D$. pteronyssinus plus anti-human TIM-1 mAb A6G2, and D. pteronyssinus plus control IgG in 96-well plates for a further 5 days. Control wells containing only $\mathrm{CD}^{+} \mathrm{T}$ cells and only myeloid DCs were also prepared. Proliferation and cytokine production were analyzed by BrdU incorporation assay (Roche) and ELISA (IL-5 and IFN- $\gamma$ ), respectively. The detection limit for the IL-5 ELISA was $1.6 \mathrm{pg} / \mathrm{ml}$ and for the IFN- $\gamma$ ELISA was $1 \mathrm{pg} / \mathrm{ml}$.

Assessment of the frequency of IL-4-producing $T$ cells. Histopaque-purified PBMCs from asthmatic donors were cultured in triplicate at a concentration of $10^{6} \mathrm{cells} / \mathrm{ml}$. Six hours prior to harvesting, Brefeldin A (Sigma-Aldrich; $10 \mu \mathrm{g} / \mathrm{ml}$ ) was applied to the cell culture. At the 72-hour time point, cells were washed twice with PBS, counted, and $10^{6}$ cells were stained with PerCPconjugated anti-CD3 mAb (BD Biosciences). Cells were then washed, fixed with Cytofix (BD Biosciences), permeabilized with 0.3\% Saponin in PBS, and stained with APC-conjugated anti-human IL-4 antibody (BD Biosciences). Cells were gated using forward- and side-scatter, and surface expression of CD3 and intracellular IL-4 was analyzed. mAbs were titered prior to use to determine optimal concentrations. Analysis was performed using Flow Cytometry instrumentation and software (BD Biosciences). 
BrdU cell proliferation assay. Cell proliferation assays were performed using a BrdU labeling and detection kit (Roche). Briefly, $10^{6}$ mononuclear cells were isolated from mouse spleen or donor PBMCs were incubated in 96-well plates for 24 hours in culture medium alone or with anti-human CD3/CD28 mAbs. $\mathrm{BrdU}$ was then added to a final concentration of $10 \mu \mathrm{M} / \mathrm{l}$. After incubation for an additional 24 hours, DNA synthesis was assayed according to the manufacturer's instructions. BrdU-labeled DNA was detected using a luminometer.

IHC. IHC staining was performed on paraffin-embedded lung tissue. Following rehydration in graded alcohol, tissue slices $(3 \mu \mathrm{m})$ were treated with either citrate (CD8, CD20, and CD68) or EDTA (CD4) solution in a microwave oven for antigen retrieval according to the antibody manufacturer's instructions. Anti-human CD4 (clone 4B12; Novocastra), antihuman CD20 (clone L26), anti-human CD68 (clone PG-M1; both Dako Cytomation), and anti-human CD8 (clone SP16; NeoMarkers) were used for the detection of specific human mononuclear cell types. The Histostain Plus kit (Invitrogen) was used for the detection of bound primary antibody and diaminobenzidine was used as chromogenic substrate.

Lung homogenization and ELISA. Snap-frozen lungs were thawed, weighed, crushed, and homogenized in $500 \mu \mathrm{l}$ of T-PER (Thermo Scientific) containing Complete Mini Protease Inhibitor Cocktail tablets (Roche; 1 tablet $/ 10 \mathrm{ml}$ of T-PER stock reagent). Lung homogenates were centrifuged at $9,000 \mathrm{~g}$ for 10 minutes at $4^{\circ} \mathrm{C}$. Total protein concentrations in supernatants were determined using a BCA kit (Thermo Scientific). The human Cytokine 11-Plex kit reagents were used to evaluate IL- $1 \beta,-2,-4,5,-6,-8,-10$, and -12 (p70), TNF- $\alpha$, TNF- $\beta$, and IFN- $\gamma$ expression patterns (BenderMed). Specific cytokine protein concentrations were expressed as $\mathrm{pg} / \mathrm{mg}$ total lung protein.
Statistics. The results are presented as mean values \pm SEM of 6-8 mice/ cohort unless otherwise stated. The Mann-Whitney $U$ test was used to determine the level of significant difference between groups. A $P$ value of 0.05 or lower was considered significant.

\section{Acknowledgments}

We thank Patricia McCoon, Steven Miklasz, and Alexey Lugovskoy for scientific input and the provision of important reagents. We acknowledge Jan Dudda for scientific input and critical review of the manuscript. We thank Joseph Amatucci, Wenjie Cheng, Attila Fabian, Judy George, Lourdes Pablo, Leticia Tarilonte, Greg Thill, Mohammad Zafari, Stefani Achenbach, Anja Spies, and Heiki Geibel for their technical expertise. We thank Andreas Neubauer and Cornelia Brendel for their scientific expertise and Thorsten Volkmann and Gavin Giel for technical assistance with the MoFlo cell sorting. This study was supported in part by the SFB/TR22 grant, project Z2, provided by the Deutsche Forschungsgemeinschaft.

Received for publication April 14, 2009, and accepted in revised form May 19, 2010.

Address correspondence to: Paul D. Rennert, Department of Immunobiology, Biogen Idec Inc., 12 Cambridge Center, Cambridge, Massachusetts 02146, USA. Phone: 617.679.2986; Fax: 617.679.2304; E-mail: paul.rennert@biogenidec.com.
1. Kay AB. Immunomodulation in asthma: mechanisms and possible pitfalls. Curr Opin Pharmacol. 2003;3(3):220-226

2. Umetsu DT, McIntire JJ, Akbari O, Macaubas C, DeKruyff RH. Asthma: an epidemic of dysregulated immunity. Nat Immunol. 2002;3(8):715-720.

3. Vercelli D. Discovering susceptibility genes for asthma and allergy. Nat Rev Immunol. 2008;8(3):169-182.

4. Ichimura T, et al. Kidney injury molecule-1 (KIM-1), a putative epithelial cell adhesion molecule containing a novel immunoglobulin domain, is upregulated in renal cells after injury. $J$ Biol Chem. 1998;273(7):4135-4142.

5. Kaplan G, Totsuka A, Thompson P, Akatsuka T, Moritsugu Y, Feinstone SM. Identification of a surface glycoprotein on African green monkey kidney cells as a receptor for hepatitis A virus. EMBOJ. 1996;15(16):4282-4296.

6. McIntire JJ, et al. Immunology: hepatitis A virus link to atopic disease. Nature. 2003;425(6958):576.

7. McIntire JJ, et al. Identification of Tapr (an airway hyperreactivity regulatory locus) and the linked Tim gene family. Nat Immunol. 2001;2(12):1109-1116.

8. Encinas JA, et al. Anti-T-cell Ig and mucin domaincontaining protein 1 antibody decreases TH2 airway inflammation in a mouse model of asthma. J Allergy Clin Immunol. 2005;116(6):1343-1349.

9. Sizing ID, et al. Epitope-dependent effect of antimurine TIM-1 monoclonal antibodies on T cell activity and lung immune responses. J Immunol. 2007;178(4):2249-2261.

10. Fukushima A, et al. Antibodies to T-cell Ig and mucin domain-containing proteins (Tim) -1 and -3 suppress the induction and progression of murine allergic conjunctivitis. Biochem Biophys Res Commun. 2007;353(1):211-216.

11. Feng BS, et al. Disruption of T-cell immunoglobulin and mucin domain molecule (TIM)-1/TIM4 interaction as a therapeutic strategy in a dendritic cell-induced peanut allergy model. J Allergy Clin Immunol. 2008;122(1):55-61.

12. Santiago C, Ballesteros A, Tami C, MartinezMunoz L, Kaplan GG, Casasnovas JM. Structures of $\mathrm{T}$ Cell immunoglobulin mucin receptors 1 and 2 reveal mechanisms for regulation of immune responses by the TIM receptor family. Immunity. 2007;26(3):299-310.

13. Santiago C, et al. Structures of T cell immunoglobulin mucin protein 4 show a metal-Ion-dependent ligand binding site where phosphatidylserine binds. Immunity. 2007;27(6):941-951.

14. Bosma GC, Custer RP, Bosma MJ. A severe combined immunodeficiency mutation in the mouse. Nature. 1983;301(5900):527-530.

15. Mosier DE, Gulizia RJ, Baird SM, Wilson DB. Transfer of a functional human immune system to mice with severe combined immunodeficiency. Nature. 1988;335(6187):256-259.

16. Carlsson R, Martensson C, Kalliomaki S, Ohlin M, Borrebaeck CA. Human peripheral blood lymphocytes transplanted into SCID mice constitute an in vivo culture system exhibiting several parameters found in a normal humoral immune response and are a source of immunocytes for the production of human monoclonal antibodies. J Immunol. 1992;148(4):1065-1071.

17. Kirchgessner CU, et al. DNA-dependent kinase (p350) as a candidate gene for the murine SCID defect. Science. 1995;267(5201):1178-1183.

18. Pestel J, et al. Human IgE in SCID mice reconstituted with peripheral blood mononuclear cells from Dermatophagoides pteronyssinus-sensitive patients. J Immunol. 1994;153(8):3804-3810.

19. Chiang BL, Chou CC, Ding HJ, Huang MS, Chen JM, Hsieh KH. Establishment of human IgE system in severe combined immunodeficient mice with peripheral blood mononuclear cells from asthmatic children. J Allergy Clin Immunol. 1995;95(1 pt 1):69-76.

20. Gagnon R, Boutin Y, Hebert J. Lol p I-specific IgE and IgG synthesis by peripheral blood mononuclear cells from atopic subjects in SCID mice. J Allergy Clin Immunol. 1995;95(6):1268-1275.

21. Steinsvik TE, Aaberge IS, Gaarder PI, Lovik M. Interleukin-13 and human immunoglobulin E production in severe combined immunodeficiency mice transplanted with human peripheral blood lymphocytes. Scand J Immunol. 1999;49(1):67-72.

22. Herz U, Daser A, Renz H. The humanized (HuPBMC) SCID mouse as an in vivo model for human $\mathrm{IgE}$ production and allergic inflammation of the skin. Int Arch Allergy Immunol. 1997;113(1-3):150-152.

23. Herz U, Botchkarev VA, Paus R, Renz H. Increased airway responsiveness, allergy-type-I skin responses and systemic anaphylaxis in a humanized-severe combined immuno-deficiency mouse model. Clin Exp Allergy. 2004;34(3):478-487.

24. Kobayashi N, et al. TIM-1 and TIM-4 glycoproteins bind phosphatidylserine and mediate uptake of apoptotic cells. Immunity. 2007;27(6):927-940.

25. Miyanishi M, Tada K, Koike M, Uchiyama Y, Kitamura T, Nagata S. Identification of Tim4 as a phosphatidylserine receptor. Nature. 2007; 450(7168):435-439.

26. Wilker PR, Sedy JR, Grigura V, Murphy TL, Murphy KM. Evidence for carbohydrate recognition and homotypic and heterotypic binding by the TIM family. Int Immunol. 2007;19(6):763-773.

27. Lauder A, McKenzie AN. Measurement of interleukin-13. Curr Protoc Immunol. 2002; Chapter 6:Unit 6.18.

28. Tournoy KG, Kips JC, Pauwels RA. The allergeninduced airway hyperresponsiveness in a humanmouse chimera model of asthma is T cell and IL-4 and IL-5 dependent. J Immunol. 2001;166(11):6982-6991.

29. Duez C, Kips J, Pestel J, Tournoy K, Tonnel AB, Pauwels R. House dust mite-induced airway changes in hu-SCID mice. Am J Respir Crit Care Med. 2000;161(1):200-206.

30. Anderson AC, Xiao S, Kuchroo VK. Tim protein structures reveal a unique face for ligand binding. Immunity. 2007;26(3):273-275.

31. Cao E, et al. T cell immunoglobulin mucin-3 crystal structure reveals a galectin-9-independent ligandbinding surface. Immunity. 2007;26(3):311-321.

32. Ichimura T, Asseldonk EJ, Humphreys BD, Gunaratnam L, Duffield JS, Bonventre JV. Kidney injury molecule- 1 is a phosphatidylserine receptor that confers a phagocytic phenotype on epithelial cells. J Clin Invest. 2008;118(5):1657-1668. 
33. DeKruyff RH, et al. T cell/transmembrane, Ig, and mucin-3 allelic variants differentially recognize phosphatidylserine and mediate phagocytosis of apoptotic cells. JImmunol. 2010;184(4):1918-1930.

34. Bree A, et al. IL-13 blockade reduces lung inflammation after Ascaris suum challenge in cynomolgus monkeys. J Allergy Clin Immunol. 2007;119(5):1251-1257.

35. Kasaian MT, Miller DK. IL-13 as a therapeutic target for respiratory disease. Biochem Pharmacol. 2008;76(2):147-155.

36. Degauque N, et al. Immunostimulatory Tim-1specific antibody deprograms Tregs and prevents transplant tolerance in mice. J Clin Invest. 2008; 118(2):735-741.
37. Han WK, Bailly V, Abichandani R, Thadhani R, Bonventre JV. Kidney Injury Molecule-1 (KIM-1): a novel biomarker for human renal proximal tubule injury. Kidney Int. 2002;62(1):237-244.

38. Degauque N, et al. Regulation of T-cell immunity by T-cell immunoglobulin and mucin domain proteins. Transplantation. 2007;84(1 suppl):S12-S16.

39. Kuchroo VK, Meyers JH, Umetsu DT, DeKruyff $\mathrm{RH}$. TIM family of genes in immunity and tolerance. Adv Immunol. 2006;91:227-249.

40. Xiao S, et al. Differential engagement of Tim-1 during activation can positively or negatively costimulate $\mathrm{T}$ cell expansion and effector function. $J$ Exp Med. 2007;204(7):1691-1702.
41. Ueno $\mathrm{T}$, et al. The emerging role of $\mathrm{T}$ cell $\mathrm{Ig}$ mucin 1 in alloimmune responses in an experimental mouse transplant model. J Clin Invest. 2008;118(2):742-751.

42. Coligan JE, Kruisbeek AM, Margulies DH, Shevach EM, Strober W, eds. Current Protocols in Immunology. New York, New York, USA: John Wiley and Sons, Inc; 1998.

43. Glaab T, et al. Tidal midexpiratory flow as a measure of airway hyperresponsiveness in allergic mice. Am J Pbysiol Lung Cell Mol Physiol. 2001;280(3):L565-L573.

44. Bunder R, et al. Induction of autoallergy with an environmental allergen mimicking a self protein in a murine model of experimental allergic asthma. J Allergy Clin Immunol. 2004;114(2):422-428. 